\title{
Comparative Effects of Graphene and Molybdenum Disulfide on Human Macrophage Toxicity
}

Hazel Lin, Ding-Kun Ji, Matteo Andrea Lucherelli, Giacomo Reina, Stefano Ippolito, Paolo Samori, Alberto Bianco*

Dr. H. Lin, Dr. D.-K. Ji., Dr. M. A; Lucherelli, Dr G. Reina, Dr. A. Bianco

CNRS, Immunology, Immunopathology and Therapeutic Chemistry, UPR 3572, University

of Strasbourg, ISIS, 67000 Strasbourg, France

E-mail: a.bianco@ibmc-cnrs.unistra.fr

S. Ippolito, Prof. P. Samorì, Dr. A. Bianco

Université de Strasbourg, CNRS, ISIS, 67000 Strasbourg, France

\begin{abstract}
Graphene and other two-dimensional (2D) materials, such as molybdenum disulfide, have been increasingly used in electronics, composites and biomedicine. In particular, $\mathrm{MoS}_{2}$ and graphene hybrids have attracted a great interest for applications in the biomedical research, therefore stimulating a pertinent investigation on their safety in immune cells like macrophages, which commonly engulf these materials. In our study, M1 and M2 macrophage viability and activation were mainly found to be unaffected by few-layer graphene (FLG) and $\mathrm{MoS}_{2}$ at doses up to 50 $\mu \mathrm{g} / \mathrm{mL}$. The uptake of both materials was confirmed by transmission electron microscopy, inductively coupled plasma mass spectrometry and inductively coupled plasma atomic emission spectroscopy. Notably, both 2D materials increased the secretion of inflammatory cytokines in M1 macrophages. At the highest dose, FLG decreased CD206 expression while $\mathrm{MoS}_{2}$ decreased CD80 expression. CathB and CathL gene expression were dose-dependently increased by both materials. Despite a minimal impact on the autophagic pathway, FLG was found to increase the expression of Atg5 and autophagic flux, as observed by western blotting of LC3-II, in M1 macrophages. Overall, FLG and $\mathrm{MoS}_{2}$ are little toxic in human macrophages even though they were found to trigger cell stress and inflammatory responses.
\end{abstract}




\section{Introduction}

Graphene has been steadily climbing the rank of scientific importance since its isolation and characterization in 2004. ${ }^{[1]}$ Graphene consists of a 2D layer of $\mathrm{sp}^{2}$-hybridized carbon atoms arranged in a hexagonal lattice, which guarantees a large surface area, in addition to many unique electronic and mechanical properties, specific magnetism and excellent conductivity. ${ }^{[2]}$ The family of graphene materials has expanded within the past two decades, including fewlayer graphene (FLG), graphene oxide (GO), reduced graphene oxide (rGO) and graphene quantum dots (GQDs). Besides their well-known and extensive use in the field of electronics, graphene derivatives have emerged in biomedical applications such as cell imaging, ${ }^{[3]}$ drug delivery, ${ }^{[4]}$ and biosensing. ${ }^{[5]}$

Within the thousands of 2D materials that have been identified upon the discovery of graphene, transition metal dichalcogenides (TMDCs), such as $\mathrm{MoS}_{2}$, became popular due to their abundance in nature (mainly as minerals, e.g. molybdenite), structural similarity to graphene and ease of exfoliation and preparation. ${ }^{[6]}$ More specifically, the tunable band gap of $\mathrm{MoS}_{2}$ encourages its development in many relevant fields within the semiconductor industry.

Notably, $\mathrm{MoS}_{2}$ and graphene hybrids have been studied and applied as anodes for lithium-ion batteries, ${ }^{[7-9]}$ electrochemical sensing of compounds ${ }^{[10]}$ and high-performance supercapacitors. [11] In view of the extended uses of such materials, it is therefore extremely important to ascertain their safety in human cells, which could be exposed to these increasingly and widely used 2D materials.

Graphene family members have been involved in a wide range of toxicity testing as reviewed by many researchers, ${ }^{[12-14]}$ with a multitude of assays conducted on cell lines, whole animals and cultured tissues. However, there has been a dearth of information on primary human immune cells, since the toxicity of bulk graphene has mainly been tested on cell lines. In addition, $\mathrm{MoS}_{2}$ is a material on which few toxicity studies have been conducted so far. It has been used in intracellular targeted reactive oxygen species (ROS) production in exploratory cancer research, ${ }^{[15]}$ and when combined with GO, it was found to produce a muted inflammatory response compared to GO alone. ${ }^{[16]}$ GO has been the most widely studied member of the graphene family and the majority of toxicity studies have often pointed out its reactive surface groups as the main cause of toxicity. ${ }^{[16,17]}$ In general, it is necessary to conduct separate investigations for the other members of the graphene family, as the diversity in sizes, shapes, surfaces, and fabrication could lead to different extents and causes of cellular toxicity. [18] 
In this paper, we used human peripheral blood monocyte-derived macrophages (HMDMs), which have been differentiated into pro-inflammatory M1 macrophages and anti-inflammatory M2 macrophages, aiming at clarifying the real-life situation of how these differing subtypes of immune cells respond to FLG and $\mathrm{MoS}_{2}$. We checked for inflammatory cytokines and activation markers, as graphene thin films were found to affect cell surface receptors in JAWSII mouse bone marrow dendritic cells. ${ }^{[19]}$ Stress response pathways, such as autophagy, were also investigated, as the latter represents an important protective mechanism that is triggered under conditions of intracellular stress, occuring during the encounters with nanomaterials. ${ }^{\text {[20] }}$

To the best of our knowledge, this is the first study to compare the effects of different $2 \mathrm{D}$ materials, FLG and $\mathrm{MoS}_{2}$, in human M1 and M2 macrophages. In our paper, we report a minimal impact on toxicity and autophagic flux, although we measure an increase in proinflammatory cytokine production and an upregulation of genes in the autophagic and related lysosomal pathway.

\section{Results and Discussion}

\subsection{Preparation and characterization of FLG and $\mathrm{MoS}_{2}$}

2D $\mathrm{MoS}_{2}$ was produced by direct liquid phase exfoliation of bulk molybdenum disulfide crystals in a riboflavin-5'-phosphate (Rib) solution using the tip sonication approach. ${ }^{[21]}$ After removal of the excess of Rib via filtering, washing and resuspension, a highly concentrated Rib$\mathrm{MoS}_{2}$ dispersion $(1 \mathrm{mg} / \mathrm{mL})$ was obtained, which resulted stable for weeks without the formation of visible agglomerates and precipitates. The suspension of the Rib-MoS 2 was then characterized by using a variety of techniques. Transmission electron microscopy (TEM) micrographs showed individual sheets with an average size of $\sim 150 \mathrm{~nm}$ (Figure 1A). The lateral size distribution was calculated from TEM images by measuring more than 300 sheets. The histogram plot of this distribution shows values ranging between 50 and $500 \mathrm{~nm}$ (Figure 1B). Atomic Force Microscopy (AFM) imaging was used to quantify the height (thickness) of Rib-MoS 2 sheets, thereafter simply referred to as $\mathrm{MoS}_{2}$. The histogram plot of the height distribution, based on more than 300 individual sheets, ranges from 3 to $19 \mathrm{~nm}$, with an average height of $8.2 \mathrm{~nm}$ (Figure S1). These two values (lateral size and thickness) are suitable for the in vitro comparative effects due to the intrinsic difference in terms of single layer thickness of $\mathrm{MoS}_{2}$ and FLG. $\mathrm{MoS}_{2}$ single layer has a thickness of $0.65 \mathrm{~nm}$, which is almost double of a graphene sheet $(0.34 \mathrm{~nm})$. The two dispersions present a comparable distribution in terms of average thickness and number of layers of the flakes. ${ }^{[22]}$ 
For the preparation of FLG, riboflavin-5'-phosphate was employed again as exfoliating agent. ${ }^{\text {[21] }}$ FLG was produced directly in water by bath sonication of graphite in a solution of Rib. Ultracentrifugation and filtration were applied to isolate the most stable sheets and remove the excess of Rib. A highly concentrated Rib-FLG dispersion ( $2 \mathrm{mg} / \mathrm{mL})$ was obtained, which remained stable for months without the formation of visible agglomerates and precipitates, analogously to $\mathrm{MoS}_{2}$. The suspension of the exfoliated graphene (thereafter simply referred to as FLG) was then characterized by TEM (Figure 1C). In particular, the lateral size distribution $(100-900 \mathrm{~nm})$ was calculated from TEM images by measuring at least 250 individual sheets of FLG (Figure 1D), exhibiting an average lateral size of $\sim 312 \mathrm{~nm}$. Concerning the thickness, high-resolution-TEM (HR-TEM) was used to extrapolate an average value of 5 layers, confirming the few-layer nature of the material and the efficiency of the exfoliation procedure (Figure S2). Z-potential measurements were performed on dispersion of FLG and $\mathrm{MoS}_{2}$ to evaluate the stability of the particles at $\mathrm{pH}$ 7. Both dispersions showed z-potentials below the threshold of $-30 \mathrm{mV}$, commonly indicated as a standard value for stable dispersions. The values correspond to $-38 \mathrm{mV}$ and $-41 \mathrm{mV}$ for FLG and $\mathrm{MoS}_{2}$, respectively. The quality of the sheets was then evaluated by Raman spectroscopy. $\mathrm{I}_{\mathrm{D}} / \mathrm{I}_{\mathrm{G}}$ ratio of FLG was calculated from the resulting averaged Raman spectra performed on a surface of $1600 \mu \mathrm{m}$ (441 spectra), giving a value of 0.35 , indicating a low amount of defects on FLG (Figure S3a). In the case of $\mathrm{MoS}_{2}$, Raman spectra displayed two characteristic bands at 381 and $407 \mathrm{~cm}^{-1}$, corresponding to the peaks of the $\mathrm{E}^{1}{ }_{2} \mathrm{~g}$ and $\mathrm{A}_{1} \mathrm{~g}$ modes of the hexagonal $\mathrm{MoS}_{2}$ crystal, respectively, confirming the good quality of $2 \mathrm{D} \mathrm{MoS} 2$ sheets (Figure S3b). ${ }^{[23]}$

\subsection{Macrophage viability and activation}

An initial check regarding the basal cytotoxicity and other relevant activation markers impacted by $\mathrm{MoS}_{2}$ and FLG was conducted, after adding both 2D materials, which were previously checked to be endotoxin-free. M1 macrophages treated for $24 \mathrm{~h}$ with increasing doses of $\mathrm{MoS}_{2}$ $(5,25,50 \mu \mathrm{g} / \mathrm{mL})$ remained unchanged in terms of viability compared to untreated control, while a slight but non-significant decrease was observed for FLG (Figure 2A). No change in viability was observed in M2 macrophages for both materials, even at the highest dose used (50 $\mu \mathrm{g} / \mathrm{mL}$ ) (Figure 2B). It is worth noting that $\mathrm{MoS}_{2}$ nanoplatelets have been previously proved to be non-toxic in mesenchymal stem cells at concentrations up to $50 \mu \mathrm{g} / \mathrm{mL}$. ${ }^{[24]}$ Our data are in agreement with previous studies, where $\mathrm{MoS}_{2}$ showed lower cytotoxicity than graphene in A549 human lung carcinoma cells, although the graphene data used in the comparison had been extrapolated from separate studies. ${ }^{[25]}$ 
Then we focused our attention on cell activation. The expression of the M1 macrophage marker CD80 was decreased after $24 \mathrm{~h}$ only at the highest dose of $50 \mu \mathrm{g} / \mathrm{mL}$ of $\mathrm{MoS}_{2}$, and at the moderate dose of $25 \mu \mathrm{g} / \mathrm{mL}$ of FLG (Figure 2C). The expression of the M2 macrophage marker CD206 was instead reduced only at the highest dose in FLG, while no change was observed at any dose with $\mathrm{MoS}_{2}$ (Figure 2D). Other studies have displayed a decrease in CD80 expression after $48 \mathrm{~h}$ incubation with GO nanosheets in murine peritoneal M1 macrophages and an increase in CD206 expression in murine M2 macrophages. ${ }^{[26]}$ For $\mathrm{MoS}_{2}$, there has been no published data on activation markers although soluble Mo alone was found to upregulate CD80 and CD86 expression in human macrophages. ${ }^{[27]}$

At the highest dose of $50 \mu \mathrm{g} / \mathrm{mL}$, FLG slightly decreased CD206 expression, while $\mathrm{MoS}_{2}$ decreased CD80. CD80 was also reduced with $25 \mu \mathrm{g} / \mathrm{mL}$ FLG. Studies of other nanoparticles have reported a decrease in CD80 secretion in primary mouse macrophages compared to untreated controls. ${ }^{[28]}$ Hypoxia has been implicated as a potential cause of macrophage CD80 downregulation, ${ }^{[29,30]}$ although extensive work is needed to verify this result.

ROS production, measured by the commercial dye CM-H2DCFDA using flow cytometry, was however increased dose-dependently in M1 macrophages only with FLG, and not with $\mathrm{MoS}_{2}$ (Figure 2E). No significant changes were instead observed in M2 cells for both materials (Figure 2F). This result was expected as ROS are important for pathogen clearing in proinflammatory M1 macrophages and less important for inflammation-resolving M2 macrophages. ${ }^{[31]}$ Previous studies have also shown that multi-layer graphene nanoplatelets induced a ROS response and slightly decreased viability, but at doses above $100 \mu \mathrm{g} / \mathrm{mL}$. ${ }^{[32]}$ Macrophages undergo oxidative stress, such as ROS production, upon foreign particle exposure, especially pro-inflammatory M1 macrophages. Being responsive to inflammatory conditions, M1 macrophages were previously found to have higher levels of ROS, compared to M2, in agreement with our data. ${ }^{[33]}$

In general, graphene-induced oxidative stress has been attributed to non-cellular factors such as particle size, shape, surface charge, functional groups and light activation, and to cell responses which include mitochondrial respiration, immune cell activation and media $\mathrm{pH}$. These parameters in turn influence ROS production. ROS are important for the activation of proinflammatory signaling pathways. ${ }^{[34]} \mathrm{MoS}_{2}$ and GO have been reported to induce ROS production in J774A.1 mouse macrophages. ${ }^{[35,36]}$ However, our results show ROS production with FLG but not with $\mathrm{MoS}_{2}$, in primary human macrophages, demonstrating that not all 2D materials are sufficiently pro-inflammatory to evoke ROS-related macrophage responses. 


\subsection{Macrophage inflammatory cytokine secretion}

The inflammatory cytokines IL-1 $\beta$, TNF- $\alpha$ and IL-6 were found to be dose-dependently increased by FLG in M1 macrophages (Figure 3A), whereas $\mathrm{MoS}_{2}$ increased the secretion of only TNF- $\alpha$ and IL-6 in M1 macrophages (Figure 3B, 3C). No secretion of IL-1 $\beta$ was observed in M2 macrophages with both materials (Figure 3D). For TNF- $\alpha$, only FLG at the highest dose $(50 \mu \mathrm{g} / \mathrm{mL})$ showed a significant increase (Figure 3E), while a non-significant increase was observed with IL-6 in M2 macrophages (Figure 3F). These results are in good agreement with the literature, although the unexpected IL-6 production in M2 macrophages could be attributed to cell heterogeneity despite similar culture conditions.

Most graphene and 2D materials produce pro-inflammatory cytokines, but we decided to also measure anti-inflammatory cytokines in order to gauge cytoprotective responses, since we had a M1 and M2 macrophage system for comparison. A dose-dependent increase in the antiinflammatory cytokine IL-10 was observed with both FLG and $\mathrm{MoS}_{2}$ in M1 (Figure 3G) and M2 macrophages, but this was significant only at the highest FLG dose $(50 \mu \mathrm{g} / \mathrm{mL})$ in M2 macrophages (Figure 3I). TGF- $\beta$, another anti-inflammatory cytokine, showed no apparent trends with the two materials due to high individual and experimental variation of cytokine levels, in both M1 and M2 macrophages (Figure 3H, 3J). In short, low doses of 2D material failed to evoke anti-inflammatory response from M2 macrophages, which was not surprising given that pro-inflammatory responses are typical cell defense mechanisms upon the encounter with foreign particles.

The presence of a foreign material, such as graphene or $\mathrm{MoS}_{2}$, in a cell might trigger the secretion of cytokines. Exposure of primary mouse macrophages to $20 \mu \mathrm{g} / \mathrm{mL}$ of graphene was previously shown to significantly increase the secretion of IL-1a, IL-6, IL-10, TNF- $\alpha$ and GMCSF. ${ }^{[37]}$ Conversely, an increase in IL- 6 but no change in TNF- $\alpha$ and IL- $1 \beta$ was observed upon the addition of single-walled carbon nanohorns in RAW mouse macrophages. ${ }^{[3]}$ However, in the case of exfoliated graphene (at a dose of $10 \mu \mathrm{g} / \mathrm{mL}$ ), IL-1 $\beta$ and TNF- $\alpha$ were found to be increased. ${ }^{[38]}$

Exfoliated $\mathrm{MoS}_{2}$, in contrast to its aggregated form, was also shown to be non-toxic in THP-1 and BEAS-2B cells, and did not induce strong pro-inflammatory responses as measured by IL8 , TNF- $\alpha$ and IL-1 $\beta$ production. ${ }^{[39]} \mathrm{MoS}_{2}$-induced IL-6 secretion has previously been reported in mouse bone marrow-derived macrophages, although at lower levels. ${ }^{[40]}$

In short, both materials increased secretion of inflammatory cytokines in M1 macrophages. This was not surprising as M1 macrophages are pro-inflammatory and M2 macrophages are anti- 
inflammatory. The presence of foreign materials such as $\mathrm{MoS}_{2}$ and FLG are therefore more likely to cause inflammatory effects and have a greater impact on M1 macrophages.

\subsection{Cell uptake of $\mathrm{MoS}_{2}$ and FLG}

Considering TEM as a gold standard technique in elucidating material uptake within cells, the subsequent step was to compare the uptake of both 2D materials in M1 and M2 macrophages. In this regard, TEM imaging revealed that both M1 and M2 macrophages exhibit cellular uptake of $\mathrm{MoS}_{2}$ and FLG (Figure 4, 5). The materials were observed to be internalized within phagocytic vacuoles, in different amounts and in varying degrees of aggregation. However, it is worth mentioning that the untreated and FLG or $\mathrm{MoS}_{2}$-treated cells appear with different contrasts in TEM imaging using the same TEM processing protocols, and therefore cannot be accurately quantified in terms of cellular uptake.

$\mathrm{MoS}_{2}$ uptake was found to involve flask-like invaginations that could be attributed to either phagocytosis or endocytosis. No apparent differences in mitochondria, in terms of distortion or damage, was observed for either FLG or $\mathrm{MoS}_{2}$ in both macrophage types.

No double-stranded autophagosome-like organelles were monitored, although electron-dense organelles resembling lysosomes were observed both in untreated controls and FLG- and $\mathrm{MoS}_{2-}$ treated M1 and M2 macrophages. This could point to a predominantly lysosomal involvement, instead of autophagy. It is well-known that different nanomaterials, even if they belong to the same graphene family, might exhibit different uptake mechanisms and engulfment fates. For example, the engulfment of so-called pristine graphene has been found to take place in lysosomal vesicles, while for single-walled carbon nanotubes it occurs in autophagic vesicles. [41] Data from the same authors also showed that $\mathrm{MoS}_{2}$ was ultimately located in single membrane vesicles in A549 lung cancer cells, AGS gastric cells and THP-1 macrophages. ${ }^{[40]}$ Interestingly, another paper demonstrated that $\mathrm{MoS}_{2}$ nanosheets, prepared using a different methodology, were found free in the cytoplasm as well as within vesicles of HeLa cells and human monocyte-derived macrophages. ${ }^{[42]}$ In contrast, no free FLG or $\mathrm{MoS}_{2}$ was observed in the cytoplasm, but only within phagocytic vacuoles.

To corroborate our qualitative TEM data, we decided to use an alternative method for a quantitative intracellular measurement of FLG and $\mathrm{MoS}_{2}$. Towards this end, we performed inductively coupled plasma mass spectrometry (ICP-MS) and inductively coupled plasma atomic emission spectroscopy (ICP-AES), which confirmed the extent of uptake. These methods were used to accurately estimate the intracellular content of FLG and $\mathrm{MoS}_{2}$ per cell. Macrophages were incubated with $50 \mu \mathrm{g} / \mathrm{mL}$ of FLG and $\mathrm{MoS}_{2}$ for $24 \mathrm{~h}$, and then treated under strong acid conditions to recover molybdenum and graphene for quantification. In this case, 
molybdenum $\left(\mathrm{Mo}^{95}\right)$ could be detected directly. Graphene could not be measured directly due to the abundance of carbon in human cells. To overcome the problem of a direct quantification of carbon derived from FLG, FLG was conjugated to silver-indium (Ag-In) quantum dots (QDs). More specifically, QDs were adsorbed onto FLG surface in a 1:10 reaction stoichiometry and characterized by TEM and the colloidal stability was evaluated via UV-vis (Figure S4 and S5). (Figure S4). The indium $\left(\mathrm{In}^{115}\right)$ taken up by the cells (in the form of FLG-QDs) was therefore measured as a gauge for the cellular uptake of FLG. Using ICP-MS and ICP-AES, no FLG or $\mathrm{MoS}_{2}$ were observed in the untreated control M1 macrophages, but a similar amount of $\mathrm{MoS}_{2}$ and FLG was found to enter M1 macrophages $\left(21.13 \pm 1.77 \mathrm{pg}\right.$ of $\mathrm{MoS}_{2}$ per single cell versus $23.82 \pm 0.99$ pg of FLG per single cell).

\subsection{Effects of FLG and $M_{0} S_{2}$ on autophagic flux}

Autophagy is an important intracellular recycling pathway that might be affected by the presence of foreign materials, such as some members of the graphene family. For instance, GO have been found to induce autophagy in RAW cells, ${ }^{[43,44]}$ while graphene quantum dots have been shown to stimulate autophagy, apoptosis and inflammation in THP-1 cells. ${ }^{[45]}$ Singlewalled carbon nanotubes and graphene oxide have also been seen to induce autophagosome accumulation and lysosome impairment in primary mouse macrophages. ${ }^{[46]}$ However, multiwalled carbon nanotubes were found to inhibit autophagy in RAW cells. ${ }^{[20]}$

Autophagic proteins, such as LC3-II, serve as a readout of autophagy, although an increase can signify either an accumulation due to blockage or an increased flux through increased cycling of autophagy. Autophagic flux can be calculated by the difference between LC3-II/ $\beta$-actin immunoblotted proteins in a sample treated with the lysosome inhibitor ammonium chloride $(\mathrm{ACH})$ and the corresponding untreated sample. ${ }^{[47]}$ In M1 macrophages, FLG but not $\mathrm{MoS}_{2}$ was observed to increase autophagic flux, although this was non-significant (Figure 6A-C). No changes were instead observed in M2 macrophages for both materials (Figure 6D-F). Since the effects on autophagy are strongly affected by the cell type and treatment, it could be that the treatment duration was too short to observe a change, or that the cells were able to regulate this effect by triggering other compensatory pathways.

\subsection{Effect of FLG and $\mathrm{MoS}_{2}$ on autophagic gene expression}

Macrophage phagocytosis triggers LC3 translocation to autophagosomes in a Atg5- and Atg7dependent manner, which is not associated with observable double-membraned organelles but 
with phagolysosomal fusion, leading to rapid lysosomal acidification. ${ }^{[48]}$ The hastening of autophagosome formation due to enhanced phagolysosomal fusion has been speculated to result in more rapid clearance of foreign material. ${ }^{[49]}$ This was in accordance with our TEM data. As such, we checked the expression of relevant autophagy and lysosomal genes using quantitative PCR.

In particular, a FLG dose-dependent $(5,50 \mu \mathrm{g} / \mathrm{mL})$ increase was observed for the expression of the autophagic gene Atg5 in M1 macrophages (Figure 7A). Similarly, a dose-dependent augmentation was observed for FLG and $\mathrm{MoS}_{2}$ with respect to Atg7 and Becn1, although this was not significant (Figure 7B, C). There was no change in Atg5 for $\mathrm{MoS}_{2}$ in $\mathrm{M} 2$ macrophages and no apparent trend was observed with FLG due again to high individual and experimental variation (Figure 7D), but a dose-dependent decrease was observed in Atg7 and Becnl for both FLG and $\mathrm{MoS}_{2}$. (Figure 7E, F) A change in autophagy gene expression, but not in autophagic flux, as measured by western blotting of proteins, could allude to material-related transcriptional regulation of autophagy.

Autophagy, as many intracellular trafficking pathways, culminates in lysosomal enzyme degradation. Nanomaterials, in particular, were shown to accumulate in lysosomes and influence lysosomal function. ${ }^{[50,51]}$ Therefore, we also checked for relevant lysosomal genes, which could be altered upon exposure to FLG or $\mathrm{MoS}_{2}$.

The transcription factor EB (Tfeb), a well-conserved cytoprotective gene crucial in innate host response, ${ }^{[52]}$ is involved in endocytosis, phagocytosis and autophagy, and has been linked to immune response in situations of cellular stress. ${ }^{[53,54]}$ Tfeb is also crucial for cytokine production in activated macrophages. ${ }^{[55]}$ Our results showed that the expression of Tfeb was increased prominently in M2 macrophages by high dose $(50 \mu \mathrm{g} / \mathrm{mL})$ of $\mathrm{MoS}_{2}$ but not by FLG (Figure 7G). A non-significant increase in Tfeb was observed in M1 macrophages for both FLG and $\mathrm{MoS}_{2}$ (Figure 7J). Expression of the lysosomal protease genes CathB and CathL was dose-dependently increased by $\mathrm{MoS}_{2}$ in both M1 and M2 macrophages (Figure 7H, I, K, L). No significant changes were monitored in FLG-treated M1 and M2 macrophages in terms of CathB expression (Figure $\mathbf{7 H}, \mathbf{K}$ ), although there was a non-significant increase in CathL expression in M1 macrophages. (Figure 7I) Cathepsins have also been implicated in inflammation, as their inhibition can lead to mitochondria stress and ROS production. In particular, Cathepsin L is required for normal lysosomal function. ${ }^{[56]}$ No decrease in cathepsin gene expression was observed in our experiments, hence indicating an optimal lysosomal function. 


\section{Conclusion}

Material uptake can occur not only via internalization through passive diffusion but also through active absorption of substances by the living tissues. ${ }^{[38]}$ Both FLG and $\mathrm{MoS}_{2}$ were observed to be taken up into primary human macrophages, with increased M1 production of inflammatory cytokines and ROS.

The biological safety of both materials was confirmed by the no significant decrease in viability in both M1 and M2 macrophages. Genes coding for the lysosomal enzymes CathB and CathL were dose-dependently increased by both materials in M1 and M2 macrophages. FLG was found to increase the expression of Atg5 and autophagic flux in M1 macrophages as measured by anti-LC3 western blotting, although an accurate TEM analysis did not reveal an increased amount of autophagosomes compared to untreated control.

We would like to underline that these materials have the potential to modulate or quench the fluorescent or the absorbance signal in various biological assays, and it is prudent to check for this before commencing experiments. It may be fortunately possible to overcome the effect of quenching by using a saturating amount of commercial dyes or conjugated antibodies.

Finally, we have presented our data considering dosed concentrations and not actual internalized concentration of materials, as the latter would display donor-to-donor variation along with experimental fluctuations. Dosed concentrations would also be easier to replicate in future studies, as the measurement of actual internalized concentration of nanomaterials can be challenging.

\section{Experimental Section}

\subsection{Preparation and characterization of $\mathrm{MoS}_{2}$}

Exfoliation of bulk $\mathrm{MoS}_{2}$ was carried out directly in MilliQ ${ }^{\circledR}$ water using $500 \mathrm{mg}$ of bulk $\mathrm{MoS}_{2}$ in $100 \mathrm{~mL}$ of a solution of riboflavin-5'-phosphate sodium salt (Sigma-Aldrich) at $1 \mathrm{mg} / \mathrm{mL}$. The aqueous dispersion of $\mathrm{MoS}_{2}$ powder was sonicated using tip sonication for $6 \mathrm{~h}$ in an ice bath. The resulting dispersion was centrifuged at $1500 \mathrm{rpm}$ (402 rcf) for $90 \mathrm{~min}$ to remove the bulk $\mathrm{MoS}_{2}$. The supernatant containing the exfoliated layers of $\mathrm{MoS}_{2}$ was collected and filtered on a $0.1 \mu \mathrm{m}$ cut-off membrane. The filter cake was washed with $200 \mathrm{~mL} \mathrm{MilliQ}^{\circledR}{ }^{\text {water }}$ for 5 times to remove the excess of Rib. The solid was then sonicated for $5 \mathrm{~min}$ in $10 \mathrm{~mL}$ of MilliQ ${ }^{\circledR}$ water to obtain the final $\mathrm{MoS}_{2}$ aqueous dispersion.

The $\mathrm{MoS}_{2}$ samples for atomic force microscopy investigations were prepared as previously described. ${ }^{[55]}$ Briefly, AFM was carried out with a Bruker Dimension Icon microscope, in tapping mode and using TESPA-V2 silicon tips with spring constant of $42 \mathrm{~N} / \mathrm{m}$. 


\subsection{Preparation and characterization of FLG and Quantum Dots (QDs)}

\section{Few-Layer Graphene}

Exfoliation of graphene was carried out directly in $\mathrm{Milli}^{\circledR}$ water using $1.5 \mathrm{~g}$ of graphite $(<20$ $\mu \mathrm{m}$; Sigma-Aldrich \#BCBS5850V) dispersed in $200 \mathrm{~mL}$ of a $1 \mathrm{mg} / \mathrm{mL}$ solution of Rib. The solution was sonicated for $5 \mathrm{~h}$, keeping the temperature $<30{ }^{\circ} \mathrm{C}$ by the replacement of warm water with ice every $30 \mathrm{~min}$, to obtain few-layer graphene. Then, the obtained dispersion was centrifuged at $5500 \mathrm{~g}$ for $1 \mathrm{~h}$ (Beckman Avant J-25) to recover the most stable graphene sheets. The supernatant containing the exfoliated layers of graphene was collected, filtered using a 0.1 $\mu \mathrm{m}$ membrane filter, and washed with $300 \mathrm{~mL}$ water to remove the excess of Rib. The powder was then sonicated for $5 \mathrm{~min}$ in $20 \mathrm{~mL}$ of MilliQ ${ }^{\circledR}$ water to obtain the final graphene dispersion (FLG-Rib).

The lateral size dimension was measured using a Hitachi 7500 transmission electron microscope (Hitachi High Technologies Corporation, Japan) equipped with an AMT Hamamatsu digital camera (Hamamatsu Photonics, Japan). High-resolution-TEM (HR-TEM) analysis was performed on a JEOL 2100F TEM/STEM electron microscope operating at 200 $\mathrm{kV}$.

\section{Quantum Dots}

Quantum dots were synthesized by controlled decomposition method, as previously reported. ${ }^{\text {[57] }}$ For the synthesis of the Ag-In QDs, $17 \mathrm{mg}$ of $\mathrm{AgNO}_{3}(0.1 \mathrm{mmol}$ ) (Sigma-Aldrich) and 88.4 $\mathrm{mg}$ of $\mathrm{InCl}_{3}(0.4 \mathrm{mmol}$, Sigma-Aldrich) were placed in a $100 \mathrm{~mL}$ round-bottom flask. Then, $190 \mu \mathrm{L}$ of oleic acid (0.6 mmol) (Sigma-Aldrich), $720 \mu \mathrm{L}$ of 1-dodecanethiol (0.6 mmol) (Sigma-Aldrich), and $8 \mathrm{~mL}$ of 1-octadecene (Sigma-Aldrich) were added under argoncontrolled atmosphere. The solution was heated at $60^{\circ} \mathrm{C}$ for $15 \mathrm{~min}$, at $90^{\circ} \mathrm{C}$ for $15 \mathrm{~min}$, and left at $110^{\circ} \mathrm{C}$, stirring until no precipitate was visible $(15-30 \mathrm{~min})$. Then, $4 \mathrm{~mL}$ of solution of elemental sulfur (9.6 mg $0.3 \mathrm{mmol}$ ) (Sigma-Aldrich) was added and the mixture turned reddish. After $15 \mathrm{~min}$, the reaction was cooled with an ice bath. The Ag-In QDs were purified by precipitation with ethanol, resuspended with cyclohexane, washed several times with ethanol/acetone and stored in $\mathrm{CH}_{2} \mathrm{Cl}_{2}$.

\section{Few-Layer Graphene-Quantum Dots}

One mg of Ag-In QDs was dispersed in $1 \mathrm{ml}$ of $\mathrm{CH}_{2} \mathrm{Cl}_{2}$ in a $20 \mathrm{~mL}$ vial. Subsequently, $1 \mathrm{~mL}$ of FLG dispersion ( $1 \mathrm{mg} / \mathrm{mL}$ in MilliQ ${ }^{\circledR}$ water) was slowly added with a micropipette allowing two-phase formation. The vial was capped with a plastic cap pierced with a syringe needle. The dispersion was left under agitation overnight. During this period, the organic phase was 
completely evaporated. The crude complex was centrifuged at 13,000 rpm for $10 \mathrm{~min}$ and the pellet was re-dispersed in fresh water. This protocol was applied three times.

\subsection{Isolation and differentiation of PBMC-derived monocytes to macrophages}

CD14+ cells were isolated from healthy donor PBMCs using a positive selection kit (Miltenyi Biotech, \#130-050-201), and differentiated to M1 macrophages using either $20 \mathrm{ng} / \mathrm{mL}$ GMCSF (Peprotech, \#300-03) or to M2 macrophages using $40 \mathrm{ng} / \mathrm{mL}$ M-CSF (Biolegend, \#574804). Polarizing cytokines were added on day 5, with $20 \mathrm{ng} / \mathrm{mL}$ LPS (Sigma, \#L2630) and $20 \mathrm{ng} / \mathrm{mL}$ IFN- $\lambda$ (Biolegend, \#570204) to M1 macrophages and $20 \mathrm{ng} / \mathrm{mL}$ IL-4 (Peprotech, \#200-04) and 20 ng/mL IL-13 (Biolegend, \#571102) to M2 macrophages. Cells were cultured in RPMI (Lonza) supplemented with 10\% heat-inactivated fetal bovine serum (FBS) and 1\% penicillin/streptomycin. Cells were treated on day 8 and analyzed on day 9.

\subsection{Transmission electron microscopy}

For TEM imaging, macrophages were cultured in 12 -well plates at a density of $1 \times 10^{6}$ cells per well and allowed to adhere before exposure to $50 \mu \mathrm{g} / \mathrm{mL} \mathrm{MoS}_{2}$ or FLG for $24 \mathrm{~h}$ along with control untreated cells. After incubation, the cells were washed with cacodylate buffer twice and then fixed in $2.5 \%$ glutaraldehyde in cacodylate buffer at $4{ }^{\circ} \mathrm{C}$ overnight. Following overnight fixation, the cells were rinsed thrice with cacodylate buffer alone. Later, the cells were post-fixed with $0.5 \%$ osmium tetroxide for $30 \mathrm{~min}$ at room temperature and were washed thrice with MilliQ ${ }^{\circledR}$ water. Cells were then dehydrated through a series of ethanol baths: $1 \times$ $25 \%$ ethanol for $10 \mathrm{~min}, 1 \times 50 \%$ ethanol for $15 \mathrm{~min}, 1 \times 70 \%$ ethanol for $15 \mathrm{~min}, 1 \times 95 \%$ ethanol for $10 \mathrm{~min}$ and $3 \times 100 \%$ ethanol for $15 \mathrm{~min}$. Following dehydration, the cells were soaked in 1:1 ratio of $100 \%$ ethanol and Epon ${ }^{\mathrm{TM}}$ overnight at $4{ }^{\circ} \mathrm{C}$. The next day, the cells were rinsed $(2 \times 4 \mathrm{~h})$ with Epon ${ }^{\mathrm{TM}}$. After soaking, final inclusion of Epon ${ }^{\mathrm{TM}}$ into the cells was done by polymerizing Epon ${ }^{\mathrm{TM}}$ at $40{ }^{\circ} \mathrm{C}$ for 30 min then incubating at $60{ }^{\circ} \mathrm{C}$ for $48 \mathrm{~h}$. Afterwards, the polymerized blocks were removed and sliced into ultrathin sections using a diamond knife attached to a ultramicrotome cutter (Leica). The ultrathin sections were then collected on copper grids coated with Butvar® B-98 and stained with $1 \%$ uranyl acetate for 30 min followed with lead citrate staining for 2 min. Grids were then examined by TEM (Hitachi H600). Control cells without $\mathrm{MoS}_{2}$ or FLG underwent the same procedure. 


\subsection{Zeta-potential}

Zeta-potential measurements were performed on a Beckman Coulter "Delsa Nano Submicron Particle Size and Zeta Potential" instrument, working at ambient conditions. FLG was dispersed at $10 \mu \mathrm{g} / \mathrm{mL}$ in milliQ ${ }^{\circledR}$ water $\left(\mathrm{pH}\right.$ 7.7) and $\mathrm{MoS}_{2}$ was dispersed at $16 \mu \mathrm{g} / \mathrm{mL}$ in $\mathrm{milliQ}^{\circledR}$ water $(\mathrm{pH} 8.2)$.

\subsection{Raman spectroscopy}

Raman spectra were recorded under ambient conditions using a Renishaw inVia spectrometer with a $532 \mathrm{~nm}$ laser and a 100× objective (numerical aperture 0.85 ). The power was kept below $1 \mathrm{~mW}$ to avoid local heating and damage effects. The samples were prepared by simply dropcasting the solutions onto a $\mathrm{SiO}_{2}-\mathrm{Si}$ substrate.

\subsection{UV-Vis measurements}

UV-Vis absorption spectra were recorded on a Cary 5000 UV-Vis-NIR spectrophotometer and were corrected for the baseline and the solvent.

\subsection{Inductively-coupled plasma mass spectrometry and inductively coupled plasma atomic emission spectroscopy}

For sample preparation, cells were incubated with either $50 \mu \mathrm{g} / \mathrm{mL}$ of $\mathrm{MoS}_{2}$ or FLG-QDs for $24 \mathrm{~h}$, then washed with PBS, harvested and freeze-dried. Pure materials (FLG-QD and $\mathrm{MoS}_{2}$ ) were analyzed and used as calibration. Single cell uptake was then estimated by dividing the amount of material obtained from ICP-MS or ICP-AES in the samples per the total number of cells.

Indium (In) and molybdenum (Mo) contents were measured by ICP-MS (7700x, Agilent Technologies) and ICP-AES (720 ES, Varian) after mineralization at $200{ }^{\circ} \mathrm{C}$ for $35 \mathrm{~min}$ under pressure (Multiwave 3000, Anton Paar) using 69\% $\mathrm{HNO}_{3}$ (TraceSELECT, Fluka Analytical) and subsequent dilution by $2 \% \mathrm{HNO}_{3}$. For ICP-MS measurements, In and Mo were detected respectively at $\mathrm{m} / \mathrm{z}=115$ and $\mathrm{m} / \mathrm{z}=95$ with rhodium $(\mathrm{m} / \mathrm{z}=103)$ as internal standard. For ICPAES measurements, emission wavelengths of In and Mo were detected at $325.609 \mathrm{~nm}$ and at $281.615 \mathrm{~nm}$, respectively.

\subsection{Flow cytometer analyses}

Viability and activation of $24 \mathrm{~h} \mathrm{MoS} 2$ or FLG-treated macrophages were assessed using flow cytometry (Beckman Coulter Gallios). Control (untreated), $\mathrm{MoS}_{2}$-treated and FLG-treated cells 
were detached with trypsin/EDTA at $37^{\circ} \mathrm{C}$ for $30 \mathrm{~min}$. Cells were washed with $2 \%$ FBS in PBS (FACS Buffer), then stained with the respective antibody mix at $4{ }^{\circ} \mathrm{C}$ for $20 \mathrm{~min}$. The antihuman antibodies used were CD14-FITC (BD, \#555397), CD11b-PE (Biolegend, \#301306), CD80-FITC (Biolegend, \#305205), CD206-FITC (BD, \#551135) and CD86-APC (BD, \#555660) to identify monocyte or macrophage populations. Viability of cells was analyzed by staining with Fixable Viability Dye (eBioscience FVD-eFluor 780, \#65-0865-14). ROS production was analyzed by staining with CM-H2DCFDA (ThermoFisher Science, \#C6827) for $30 \mathrm{~min}$ at $37^{\circ} \mathrm{C}$. After staining, cells were washed twice with FACS buffer, then resuspended in FACS buffer and analyzed on the flow cytometer.

\subsection{ELISA}

Secretion of the cytokines IL-6 (BD Opt-EIA \#555220), IL-1 $\beta$ (BD Opt-EIA \#557953), TNF (BD Opt-EIA \#555212), IL-10 (BD Opt-EIA \#555157), TGF- $\beta$ (BD Opt-EIA \#559119), IL-12 (BD Opt-EIA \#555183), treated with different concentrations of $\mathrm{MoS}_{2}$ and FLG (i.e. 5, 25, 50 $\mu \mathrm{g} / \mathrm{mL}$ ), were assayed with ELISA kits according to the manufacturer's instructions. For endotoxin testing, PolymyxinB solution was added at $10 \mu \mathrm{M}$ (Sigma, \#81271) for $24 \mathrm{~h}$ on day 3, with or without tested material. Culture supernatants were then analysed for TNF using ELISA. In short, polyvinyl microtiter 96-well plates (Falcon) were coated overnight at $4{ }^{\circ} \mathrm{C}$ with $50 \mu \mathrm{L} /$ well of purified capture antibodies diluted in coating buffer (carbonate/bicarbonate buffer $0.05 \mathrm{M}$, pH 9.6). After washing with PBS containing 0.05\% Tween (PBS-T), a blocking step was performed by adding 5\% FBS in PBS (100 $\mu \mathrm{L} /$ well $)$ for $1 \mathrm{~h}$ at room temperature. After washing thrice with PBS-T, $50 \mu$ l of culture supernatants from the treated macrophages were added in the respective wells for $2 \mathrm{~h}$ at room temperature, along with a respective series of standards as provided in the kits. The plates were then washed five times with PBS-T. Secondary antibodies as provided in the kit were then added together with HRP reagent and incubated for $1 \mathrm{~h}$ at room temperature. Then, the plates were washed five times with PBS-T, and the presence of cytokines in the tested supernatants was visualized by adding tetramethylbenzidine (TMB) in the presence of $\mathrm{H}_{2} \mathrm{O}_{2}$. The resulting absorbance was measured at $450 \mathrm{~nm}$ after stopping the reaction with $2 \mathrm{~N} \mathrm{H}_{2} \mathrm{SO}_{4}$, after 15 min.

\subsection{Western blot}

To evaluate autophagic activity, whole cell proteins were extracted from macrophages treated with low $(5 \mu \mathrm{g} / \mathrm{mL})$ and high $(50 \mu \mathrm{g} / \mathrm{mL})$ concentrations of $\mathrm{MoS}_{2}$ or FLG for $24 \mathrm{~h}$, and with or without $5 \mu \mathrm{M}$ ammonium chloride for the last 3h, using Laemmli buffer (Tris-HCl $125 \mathrm{mM} \mathrm{pH}$ 
$6.8,2 \%(\mathrm{w} / \mathrm{v})$ sodium dodecyl sulfate (SDS); $10 \%(\mathrm{v} / \mathrm{v})$ glycerol; $5 \%(\mathrm{v} / \mathrm{v}) \beta$-mercaptoethanol). Cell lysates were separated on a 4-20\% gradient gel (Biorad) and then transferred onto a polyvinylidene difluoride (PVDF) membrane. Cell membranes were blocked with PBS containing $0.1 \%(\mathrm{v} / \mathrm{v})$ Tween $20(\mathrm{PBS}-\mathrm{T})$ and $5 \%(\mathrm{w} / \mathrm{w})$ non-fat dry milk for $1 \mathrm{~h}$ and incubated $50 \mathrm{~min}$ at $4{ }^{\circ} \mathrm{C}$ with $1 \mu \mathrm{g} / \mathrm{mL}$ anti-LC3 antibody in PBS-T containing 5\% non-fat dry milk. The antibodies used for western immunoblotting were specific for the LC3 autophagic marker (Abcam, \#ab51520) and the $\beta$-actin loading control (Santa Cruz Biotechnology, \#47778). After washing with PBS-T, the membranes were incubated for $30 \mathrm{~min}$ at room temperature with goat anti-rabbit IgG antibody (Southern Biotech, \#1030-05) conjugated to horseradish peroxidase (HRP). The signal was detected using enhanced chemiluminescence detection reagents (Immobilon Western, Merck Millipore, Darmstadt, Germany, \#WBKLS0500) and visualized on radiographic film in a Kodak processor (\#M35-M X-OMAT, Rochester, NY).

\subsection{Quantitative PCR}

Total RNA was extracted using a NucleoSpin-RNA Plus kit (Macherey-Nagel, \#740984.50) according to manufacturer's instructions then converted to cDNA using the ImProm-II Reverse Transcription Set (Promega, \#A3802). Two hundred nanograms of cDNA per reaction was used for real-time PCR on a StepOne machine (Applied Biosystems), with respective primers (shown below) and the RT ${ }^{2}$ SYBR Green ROX FAST Mastermix (Qiagen, \#330623). Amplification was performed at $95^{\circ} \mathrm{C}$ for $10 \mathrm{~min}$, then 40 cycles of $15 \mathrm{~s}$ at $95^{\circ} \mathrm{C}$ and $1 \mathrm{~min}$ at $60^{\circ} \mathrm{C}$. Relative mRNA quantifications were calculated using the established $\Delta \Delta \mathrm{CT}$ method ${ }^{[58]}$ with GADPH as housekeeping control. Results shown represent $2^{-\Delta \Delta \mathrm{CT}}$ values where one control sample per plate is arbitrarily equal to 1 (Table 1 ).

Table 1. List of the primers used

\begin{tabular}{|l|l|l|l|}
\hline Primer & Sequence & Primer & Sequence \\
\hline GADPH F & GGAGCGAGATCCCTCCAAAAT & Cathepsin B F & CCAGGGAGCAAGACAGAGAC \\
\hline GADPH R & GGCTGTTGTCATACTTCTCATGG & Cathepsin B R & GAGACTGGCGTTCTCCAAAG \\
\hline ATG5 F & GCTTCGAGATGTGTGGTTTGG & Cathepsin L F & GCTAATGACACCGGCTTTGT \\
\hline ATG5 R & ACTTTGTCAGTTACCAACGTCA & Cathepsin L R & TTTCAAATCCGTAGCCAACC \\
\hline ATG7 F & ATGATCCCTGTAACTTAGCCCA & TFEB F & GTAGGACTGCACCTTCAACACCT \\
\hline ATG7 R & CACGGAAGCAAACAACTTCAAC & TFEB R & TCACGCATAGGGTTGCGCAT \\
\hline BECN1 F & GGCTGAGAGACTGGATCAGG & & \\
\hline BECN1 R & CTGCGTCTGGGCATAACG & & \\
\hline
\end{tabular}

\subsection{Statistical analysis}

Experiments were conducted at least three times and the data were processed by GraphPad Prism 7. Results are expressed as mean \pm standard deviations (SD). One-way ANOVA followed 
by Bonferroni's test was performed to determine the statistical differences among samples versus control untreated cells $(*, \mathrm{p} \leq 0.05 ; * *, \mathrm{p} \leq 0.01, * * *, \mathrm{p} \leq 0.001)$. 


\section{Supporting Information}

Supporting Information is available from the Wiley Online Library or from the authors.

\section{Acknowledgements}

The authors gratefully acknowledge the financial support from the EU Graphene Flagship project (no. 785219). This work was partly supported by the Agence Nationale de la Recherche (ANR) through the LabEx project Chemistry of Complex Systems (ANR-10-LABX0026_CSC), and through the program "Investissements d'Avenir" (ANR-11-EQPX-022). We wish to acknowledge the Centre National de la Recherche Scientifique (CNRS) and the International Center for Frontier Research in Chemistry (icFRC). The authors wish to thank C. Royer and V. Demais for TEM analyses at the Plateforme Imagerie in Vitro at the INCI (Strasbourg, France), I. El Masoudi for the ICP-MS and ICP-AES measurements, and S. Guo for the exfoliation of $\mathrm{MoS}_{2}$.

Received: ((will be filled in by the editorial staff))

Revised: ((will be filled in by the editorial staff)) Published online: ((will be filled in by the editorial staff))

\section{References}

[1] K. S. Novoselov, A. K. Geim, S. V. Morozov, D. Jiang, Y. Zhang, S. V. Bubonos, I. V. Grigorieva, A. A. Firsov. Electric Field Effect in Atomically Thin Carbon Films. Science. 2004, $306,666$.

[2] Neto AC, Guinea F, Peres NM, Novoselov KSS, Geim AK. The electronic properties of graphene. Rev Mod Phys. 2009, 81,109-162.

[3] Y. Tahara, M. Nakamura, M. Yang, M. Zhang, S. Iijima, M. Yudasaka. Lysosomal membrane destabilization induced by high accumulation of single-walled carbon nanohorns in murine macrophage RAW 264.7. Biomaterials. 2012, 33(9), 2762-9.

[4] M.H. Zainal-Abidin, M. Hayyan, G.C. Ngoh, W.F. Wong. Doxorubicin Loading on Functional Graphene as a Promising Nanocarrier Using Ternary Deep Eutectic Solvent Systems. ACS Omega. 2020, 5(3),1656-1668. 
[5] J. Huang, L. Zhang, R.P. Liang, J.D. Qiu. "On-off" switchable electrochemical affinity nanobiosensor based on graphene oxide for ultrasensitive glucose sensing. Biosens. Bioelectron. 2012, 33(8), 8017-8025.

[6] X. Huang, Z. Zeng, H. Zhang. Metal dichalcogenide nanosheets: preparation, properties and applications. Chem. Soc. Rev. 2013, 42, 1934.

[7] Riyanto, I. Sahroni, K. Bindumadhavan, P. Chang, R. Doong. Boron Doped Graphene Quantum Structure and MoS2 Nanohybrid as Anode Materials for Highly Reversible Lithium Storage. Front Chem. 2019, 7, 116.

[8] S. Wang, R. Wang, Q. Zhao, L.Ren, J. Wen, J. Chang, X. Fang, N. Hub, C. Xu. Freezedrying induced self-assembly approach for scalable constructing MoS2/graphene hybrid aerogels for lithium-ion batteries. J Colloid Interface Sci. 2019, 544, 37-45.

[9] S. Yang, J. Zhang, T. Tan, Y. Zhao, N. Liu, H. Li. A 3D MoS2/Graphene Microsphere Coated Separator for Excellent Performance Li-S Batteries. Materials (Basel). 2018, 11, 2064. [10] K.J. Huang KJ, et al. Electrochemical sensing based on layered MoS2-graphene composites. Sensors and Actuators B: Chem. 2013, 178, 671-677.

[11] E.G.S. Firmiano, A.C. Rabelo , C.J. Dalmaschio, A.N. Pinheiro, E.C. Pereira, W.H. Schreiner, E.R. Leite. Supercapacitor Electrodes Obtained by Directly Bonding 2D MoS2 on Reduced Graphene Oxide. Adv. Energy Mater. 2014, 4, 1301380.

[12] A. Bianco. Graphene: Safe or Toxic? The Two Faces of the Medal. Angew. Chem. Int. Ed. 2013, 52, 4986-4997.

[13] M. Ema, M. Gamo, K. Honda. A review of toxicity studies on graphene-based nanomaterials in laboratory animals. Regulatory Toxicology and Pharmacology. 2017, 85, 7e24. [14] X. Yuan, X. Zhang, L. Sun, Y. Wei, X.Wei. Cellular Toxicity and Immunological Effects of Carbon-based Nanomaterials. Particle and Fibre Toxicology. 2019, 16, 18.

[15] D. Ji, Y. Zhang, Y. Zang, J. Li, G. Chen, X. He, H. Tian. Targeted Intracellular Production of Reactive Oxygen Species by a 2D Molybdenum Disulfide Glycosheet. Adv. Mater. 2016, 28, 9356-9363.

[16] Y. Liu, J. Peng, S. Wang, M. Xu, M. Gao, T. Xia, J. Weng, A. Xu, S. Liu. Molybdenum disulfide/graphene oxide nanocomposites show favorable lung targeting and enhanced drug loading/tumor-killing efficacy with improved biocompatibility. NPG Asia Materials. 2018, 10, e458.

[17] L. Ou, B. Song, H. Liang, J. Liu, X. Feng, B. Deng, T. Sun, L. Shao. Toxicity of graphenefamily nanoparticles: a general review of the origins and mechanisms. Particle and Fibre Toxicology. 2016, 13, 57. 
[18] X. Guo, N. Mei. Assessment of the toxic potential of graphene family nanomaterials. $J$ Food Drug Anal. 2014, 22(1), 105-115.

[19] Z.A. Nima, K.B. Vang, D. Nedosekin, G. Kannarpady, V. Saini, S.E. Bourdo, W. Majeed, F. Watanabe, E. Darrigues, K.M. Alghazali, R.A. Alawajji, D. Petibone, S. Ali, A.R. Biris, D. Casciano, A. Ghosh, G. Salamo, V. Zharov, A.S. Biris. Quantification of cellular associated graphene and induced surface receptor responses. Nanoscale. 2019, 11, 932-944.

[20] V. Cohignac, M.J. Landry, A. Ridouxa, M. Pinault, B. Annangi, A. Gerdilc, N. HerlinBoimec, M. Maynec, M. Harutad, P. Codogno, J. Boczkowski, J. Pairona, S. Lanone. Carbon nanotubes, but not spherical nanoparticles, block autophagy by a shape-related targeting of lysosomes in murine macrophages. Autophagy. 2018, 14(8), 1323-1334.

[21] A. Ruiz, M.A. Lucherelli, D. Murera, D. Lamon, C. Ménard-Moyon, A. Bianco. Toxicological evaluation of highly water dispersible few-layer graphene in vivo. Unpublished data.

[22] Li X, Zhu H. Two-dimensional MoS2: Properties, preparation, and applications. J Materiomics. 2015, 1(1), 33-44.

[23] C. Lee, H. Yan, L. E. Brus, T. F. Heinz, J. Hone, S. Ryu. Anomalous Lattice Vibrations of Single- and Few-Layer MoS 2 . ACS Nano. 2010, 4, 2695.

[24] J.T. Rashkow, Y. Talukdar, G. Lalwani, B. Sitharaman. Interactions of 1D- and 2D-layered inorganic nanoparticles with fibroblasts and human mesenchymal stem cells. Nanomedicine (Lond). 2015, 10(11), 1693-706.

[25] W.Z. Teo, E.L.K. Chng, Z. Sofer, M. Pumera. Cytotoxicity of Exfoliated Transition-Metal Dichalcogenides (MoS2, WS2, and WSe2) is Lower Than That of Graphene and its Analogues. Chemistry. 2014, 20(31), 9627-32.

[26] M.J. Feitoa, R. Diez-Orejasb, M. Cicuéndez, L. Casarrubiosa, J.M. Rojoe, M.T. Portolésa. Characterization of M1 and M2 polarization phenotypes in peritoneal macrophages after treatment with graphene oxide nanosheets. Colloids Surf B Biointerfaces. 2019, 176, 96-105.

[27] Caicedo MS, et al. Soluble ions more than particulate cobalt - alloy implant debris induce monocyte costimulatory molecule expression and release of proinflammatory cytokines critical to metal - induced lymphocyte reactivity. J Biomed Mater Res A. 2010, 93(4), 1312-21.

[28] R. Kuo, E. Saito, S.D. Miller, L.D. Shea. Peptide-Conjugated Nanoparticles Reduce Positive Co-stimulatory Expression and T Cell Activity to Induce Tolerance. Mol Ther. 2017, 25(7), 1676-1685. 
[29] N. Lahat, M.A. Rahat, M. Ballan, L. Weiss-Cerem, M. Engelmayer, H. Bitterman. Hypoxia reduces CD80 expression on monocytes but enhances their LPS-stimulated TNF-alpha secretion. J Leukoc Biol. 2003, 74(2), 197-205.

[30] F. Raggi, S. Pelassa, D. Pierobon, F. Penco, M. Gattorno, F. Novelli, A. Eva, L. Varesio, M. Giovarelli, M.C. Bosco. Regulation of Human Macrophage M1-M2 Polarization Balance by Hypoxia and the Triggering Receptor Expressed on Myeloid Cells-1. Front Immunol. 2017, 8, 1097.

[31] H.Y. Tan, N. Wang, S. Li, M. Hong, X. Wang, Y. Feng. The Reactive Oxygen Species in Macrophage Polarization: Reflecting Its Dual Role in Progression and Treatment of Human Diseases. Oxid Med Cell Longev. 2016, 2795090.

[32] E. Demir, R. Marcos. Toxic and genotoxic effects of graphene and multi-walled carbon nanotubes. J Toxicol Environ Health A. 2018, 81(14), 645-660.

[33] B. Griess, S. Mir, K. Datta, M. Teoh-Fitzgerald. Scavenging reactive oxygen species selectively inhibits M2 macrophage polarization and their pro-tumorigenic function in part, via Stat3 suppression. Free Radic Biol Med. 2020, 147:48-60.

[34] T. A. Tabish, S. Zhang, P. G. Winyard. Developing the next generation of graphene-based platforms for cancer therapeutics: The potential role of reactive oxygen species. Redox Biology. 2018, 15, 34-40.

[35] Y. Liu, J. Peng, S. Wang, M. Xu, M. Gao, T. Xia, J. Weng, A. Xu, S. Liu.. Molybdenum disulfide/graphene oxide nanocomposites show favorable lung targeting and enhanced drug loading/tumor-killing efficacy with improved biocompatibility. NPG Asia Materials. 2018, 10, e458.

[36] G. Qu, S. Liu, S. Zhang, L. Wang, X. Wang, B. Sun, N. Yin, X. Gao, T. Xia, J. Chen, G.B. Jiang. Graphene Oxide Induces Toll-like Receptor 4 (TLR4)-Dependent Necrosis in Macrophages. ACS Nano. 2013, 7(7), 5732-45.

[37] H. Zhou, K. Zhao, W. Li, N. Yang, Y. Liu, C. Chen, T. Wei. The interactions between pristine graphene and macrophages and the production of cytokines/chemokines via TLR- and NF-kB-related signaling pathways. Biomaterials. 2012, 33(29), 6933-42.

[38] K. Fujita, S. Take, R. Tani, J. Maru, S Obara, S. Endoh. Assessment of cytotoxicity and mutagenicity of exfoliated graphene. Toxicology in Vitro. 2018, 52, 195-202.

[39] X. Wang, N.D. Mansukhani, L.M. Guiney, Z. Ji, C.H. Chang, M. Wang, Y. Liao, T. Song, B. Sun, R. Li, T. Xia, M.C. Hersam, A.E. Nel. Differences in the Toxicological Potential of Two-Dimensional versus Aggregated Molybdenum Disulfide in the Lung. Small. 2015, 11(38), 5079-5087. 
[40] C. Moore, D. Movia, R.J. Smith, D. Hanlon, F. Lebre, E.C Lavelle, H.J. Byrne, J.N. Coleman, Y. Volkov, J. McIntyre. Industrial grade 2D molybdenum disulphide (MoS2): an in vitro exploration of the impact on cellular uptake, cytotoxicity, and inflammation. $2 \mathrm{D}$ Mater. 2017, 4, 025065 .

[41] J. McIntyre, N.K. Verma, R.J. Smith, C. Moore, H. Nerl, N. McEvo, N, Berner, I. McGovern, U. Khan, P. Lyons, L. O’Neill, V. Nicolosi, G.S. Duesberg, H.J. Bryne, J. Coleman, Y. Volkov. A comparison of catabolic pathways induced in primary macrophages by pristine single walled carbon nanotubes and pristine graphene. RSC Advances. 2016, 6, 65299-65310. [42] R. Kurapati, L. Muzi, R.G. Perez, J. Russier, D. Voiry, I.A. Vacchi, M. Chhowalla, A. Bianco. Enzymatic Biodegradability of Pristine and Functionalized Transition Metal Dichalcogenide MoS2 Nanosheets. Adv. Funct. Mater. 2017, 1605176.

[43] C.S. Park, K.S. Choi, I.W. Park, J. Jung, J.C. Choi, J.Y. Kim, B.W. Choi, Y.G. Kim, J.W. Shin, S.Y. Kim. Autophagy in RAW264.7 Cells Treated with Surface-Functionalized Graphene Oxides. J Nanomaterials. 2015, 704789.

[44] G. Chen, H. Yang, C. Lu, Y. Chao, S. Hwang, C. Chen, K. Lo, L. Sung, W. Luo, H. Tuan, Y. Hu. Simultaneous induction of autophagy and toll-like receptor signaling pathways by graphene oxide. Biomaterials. 2012, 33, 6559e6569.

[45] Y. Qin, Z. Zhou, S. Pan, Z. He, X. Zhang, J. Qiu, W. Duan, T. Yang, S. Zhou. Graphene quantum dots induce apoptosis, autophagy, and inflammatory response via p38 mitogenactivated protein kinase and nuclear factor- $\kappa \mathrm{B}$ mediated signaling pathways in activated THP1 macrophages. Toxicology. 2015, 327, 62-76.

[46] B. Wan, Z. Wang, Q. Lv, P. Dong, L. Zhao, Y. Yang, L. Guo. Single-walled carbon nanotubes and graphene oxides induce autophagosome accumulation and lysosome impairment in primarily cultured murine peritoneal macrophages. Toxicol Lett. 2013, 221(2), 118-27.

[47] D.J. Klionsky, A. Abdelmohsen, A. Akihisa, et al. Guidelines for the use and interpretation of assays for monitoring autophagy (3rd edition). Autophagy. 2016, 12(1), 1-222.

[48] M. Sanjuan, C. Dillon, S. Tait, S. Moshiach, F. Dorsey, S. Connell, M. Komatsu, K. Tanaka, J.L. Cleveland, S. Withoff, D.R. Green. Toll-like receptor signalling in macrophages links the autophagy pathway to phagocytosis. Nature. 2007, 450, 1253-1257.

[49] N. Germic, Z. Frangez, S. Yousefi, S. Hu. Regulation of the innate immune system by autophagy: monocytes, macrophages, dendritic cells and antigen presentation. Cell Death \& Differentiation. 2019, 26, 715-727.

[50] W. Zheng, M. Wei, S. Li, and W. Le, Nanomaterial-modulated autophagy: Underlying mechanisms and functional consequences. Nanomedicine (Lond). 2016, 11, 1417. 
[51] J. Wang, Y. Yu, K. Lu, M. Yang, Y. Li, X. Zhou, and Z. Sun, Silica nanoparticles induce autophagy dysfunction via lysosomal impairment and inhibition of autophagosome degradation in hepatocytes. Int. J. Nanomedicine. 2017, 12, 809.

[52] O. Visvikis, N. Ihuegbu, S.A. Labed, L.G. Luhachack, A.F. Alves, A.C. Wollenberg, L.M. Stuart, G.D. Stormo, J.E. Irazoqui. Innate host defense requires TFEB-mediated transcription of cytoprotective and antimicrobial genes. Immunity. 2014, 40(6), 896-909.

[53] N.R. Nabar, J.H. Kehrl. The Transcription Factor EB Links Cellular Stress to the Immune Response. Yale J Biol Med. 2017, 90(2), 301-315.

[54] C. Settembre, C. Di Malta, V.A. Polito, M.G. Arencibia, F. Vetrini, S. Erdin, S.U. Erdin, T. Huynh, D. Medina, P. Colella, M. Sardiello, D.C. Rubinsztein, A. Ballabio. TFEB Links Autophagy to Lysosomal Biogenesis. Science. 2011, 332(6036), 1429-1433.

[55] N. Pastore, O.A. Brady, H.I. Dia, J.A. Martina, L. Sun, T. Huynh, J. Lim, H. Zare, N. Raben, A. Ballabio, R. Puertollano. TFEB and TFE3 cooperate in the regulation of the innate immune response in activated macrophages. Autophagy. 2016, 12(8), 1240-58.

[56] T. Weiss-Sadana, D. Maimoun, D. Oelschlagel, F. Kaschani, D. Misiak, H. Gaikwad, Y. Ben-Nun, E. Merquiola, A. Anaki, D. Tsvirkun, M. Kaiser, P. Michl, I. Gotsman, G. Blum. Cathepsins Drive Anti-Inflammatory Activity by Regulating Autophagy and Mitochondrial Dynamics in Macrophage Foam Cells. Cell Physiol Biochem. 2019, 53(3), 550-572.

[57] G. Reina, A. Ruiz, D. Murera, Y. Nishina, A. Bianco. "Ultramixing": A Simple and Effective Method To Obtain Controlled and Stable Dispersions of Graphene Oxide in Cell Culture Media. ACS Appl. Mater. Interfaces. 2019, 11, 8, 7695-7702.

[58] M. W. Pfaffl. A new mathematical model for relative quantification in real-time RT-PCR. Nucleic Acids Research. 2001, 29, 900. 
A

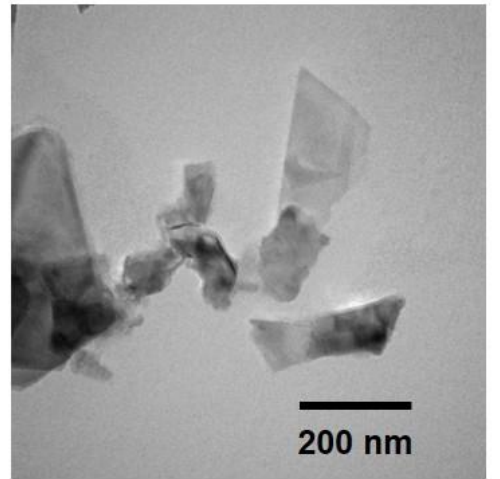

C

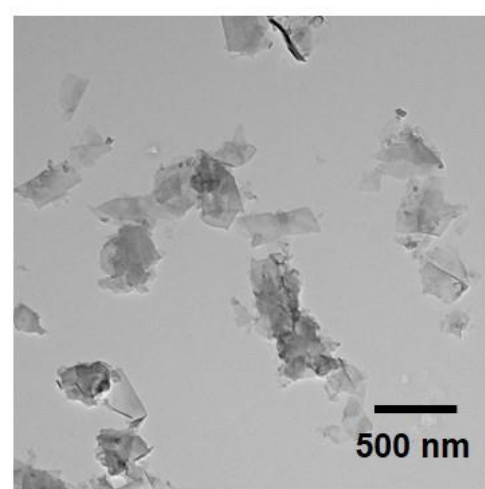

B

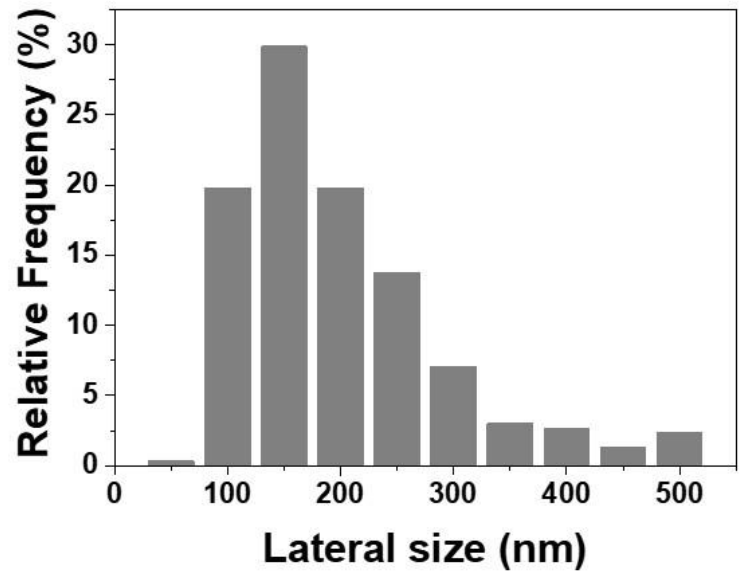

D

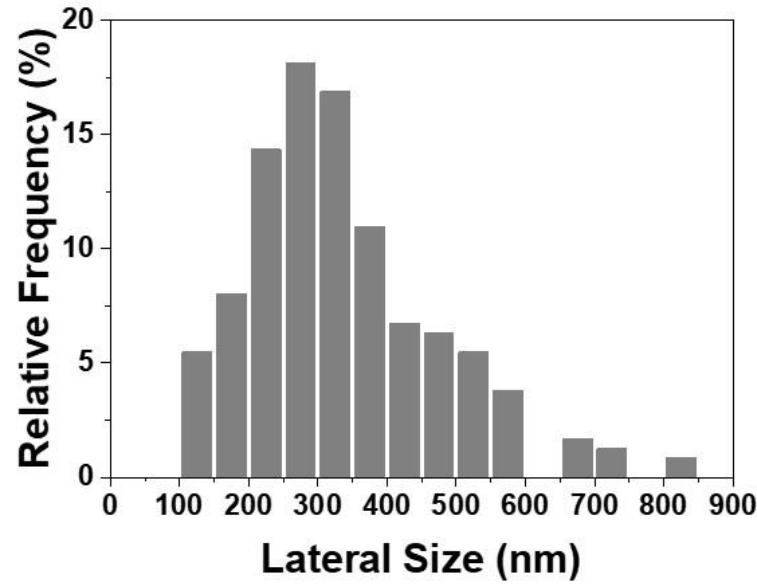

Figure 1. Material characterization. (A) TEM image of $\mathrm{MoS}_{2}$. (B) $\mathrm{MoS}_{2}$ size distribution. (C) TEM image of FLG. (D) FLG size distribution. 
A

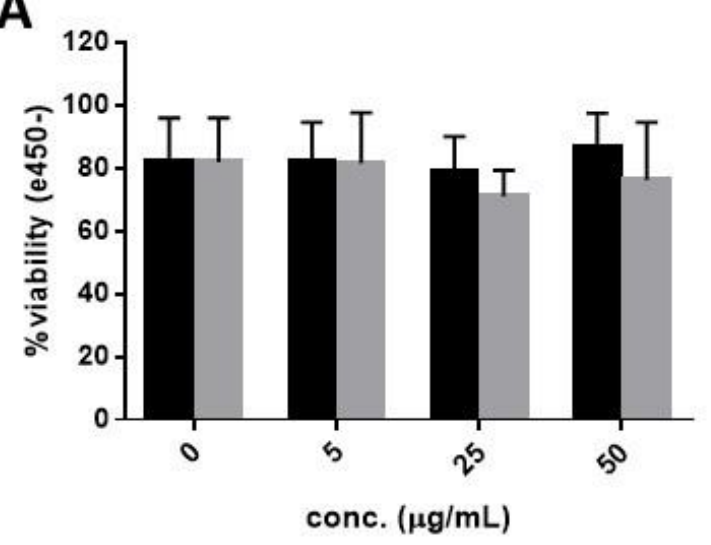

C
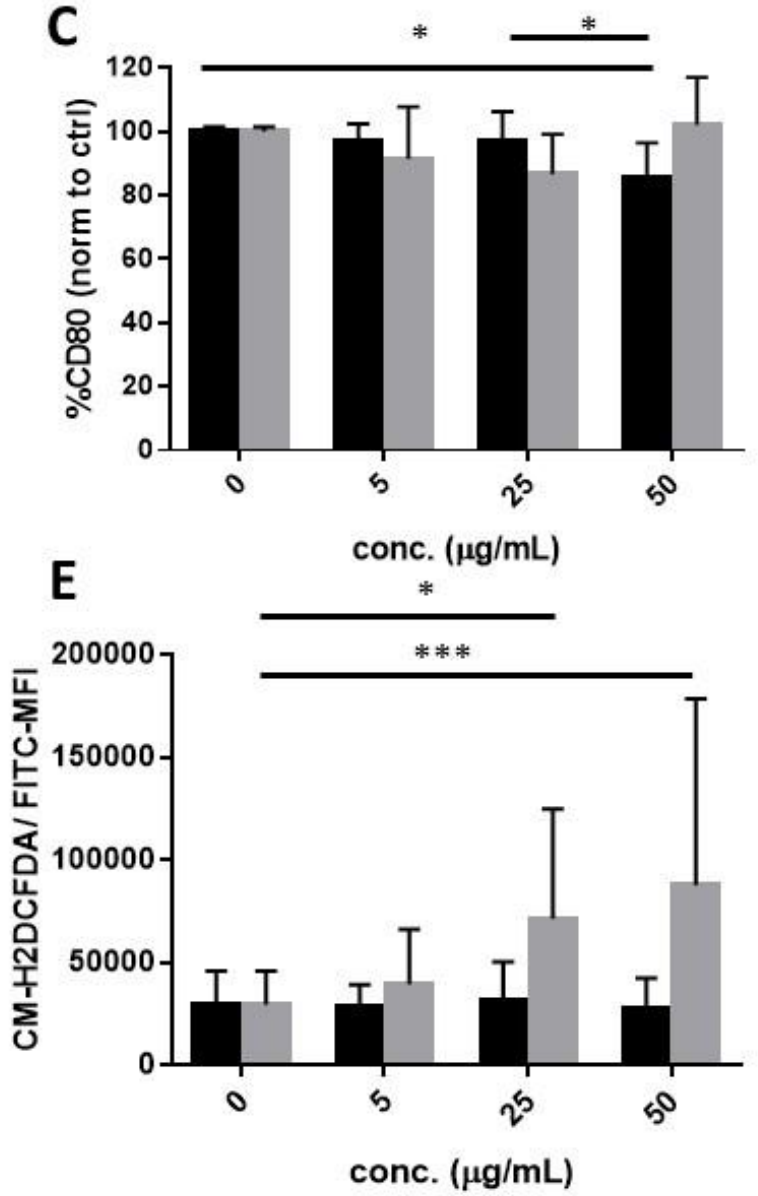

B

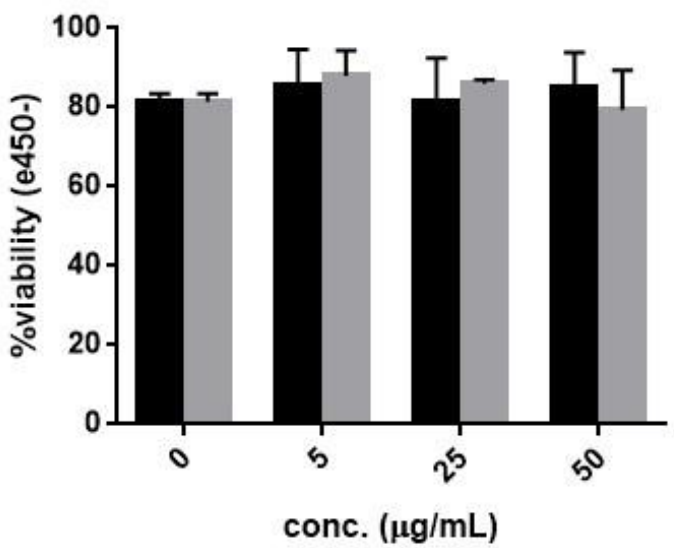

D

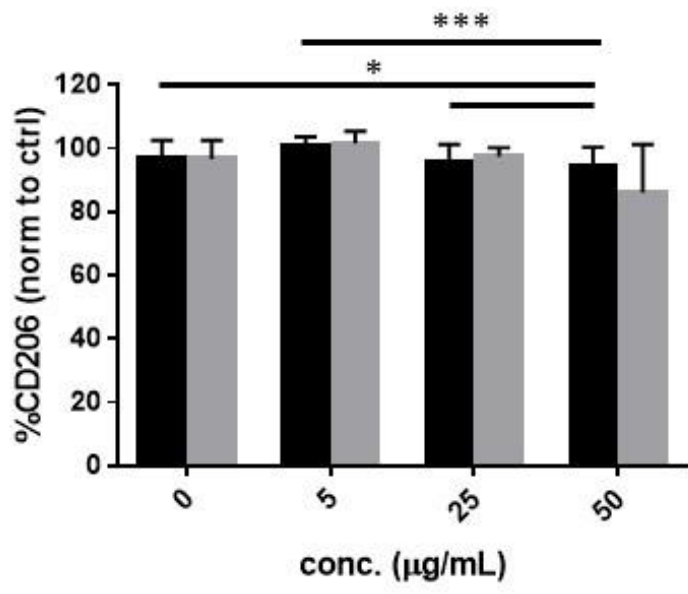

$\mathbf{F}$

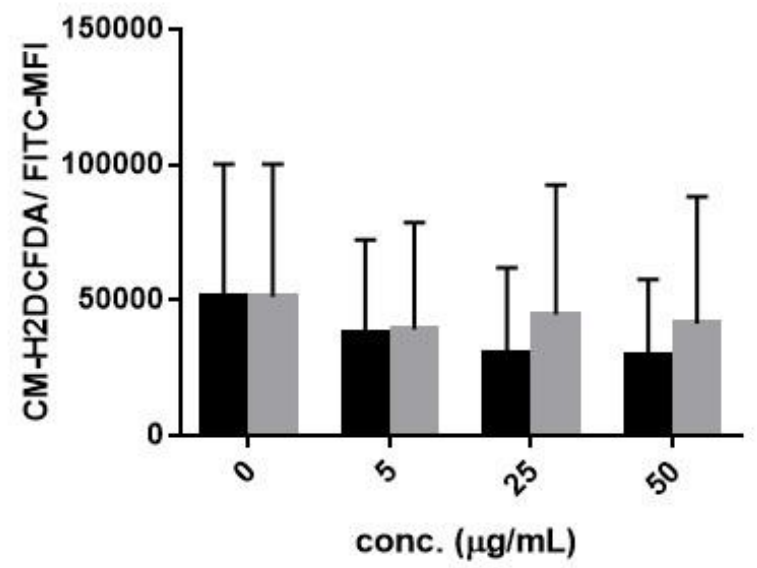

Figure 2. Macrophage viability and activation. (A) $\mathrm{MoS}_{2}$ or FLG-treated M1 macrophages were fixed, then incubated with e $450 \mathrm{FVD}$, and analyzed by flow cytometry. (B) $\mathrm{MoS}_{2}$ or FLGtreated M2 macrophages were fixed, then incubated with e450 FVD, and analyzed by flow cytometry. (C) M1 macrophages were fixed then stained with M1 surface marker CD80, and analyzed by flow cytometry. (D) M2 macrophages were fixed then stained with M2 surface marker CD206, and analyzed by flow cytometry. (E) M1 macrophages were stained with CMH2DCFDA for 30 min and analyzed by flow cytometry. (F) M2 macrophages were stained with CM-H2DCFDA for $30 \mathrm{~min}$ and analyzed by flow cytometry. Black bars correspond to $\mathrm{MoS}_{2}$ and gray bars correspond to FLG. All experiments were performed on M1 or M2 macrophages for $24 \mathrm{~h}$ with the respective conditions in triplicate and shown as mean $\pm \mathrm{SD}$. $* \mathrm{P}<0.05 ; * * \mathrm{P}<0.01, * * * \mathrm{P}<0.001$ by one-way ANOVA with Bonferroni post-tests. 
A

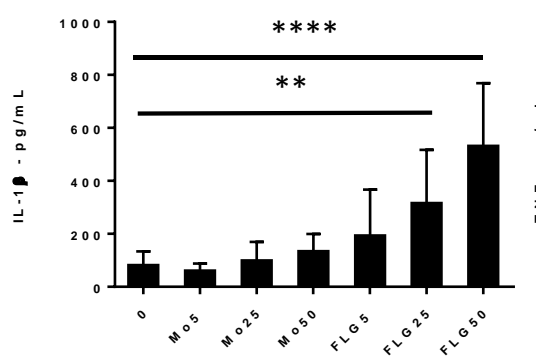

D

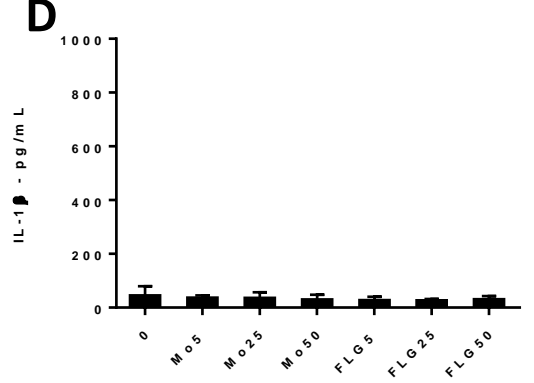

G

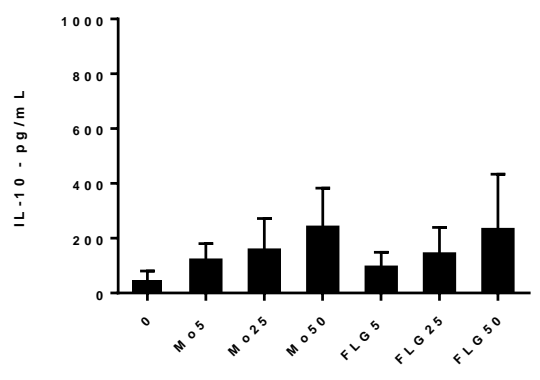

I

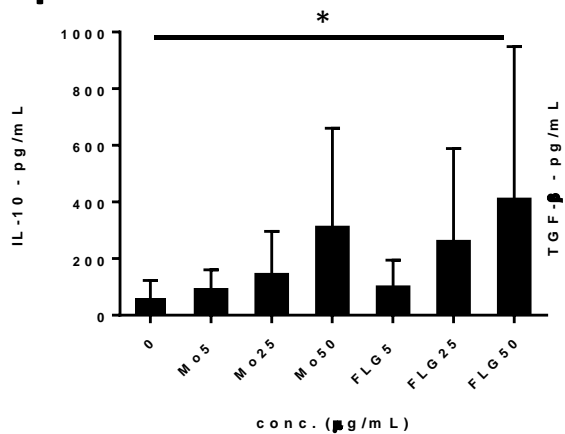

B

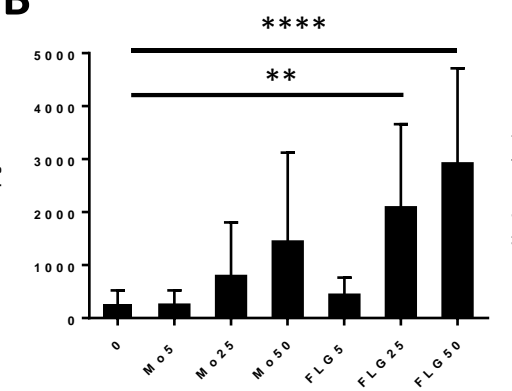

$\mathbf{E}$

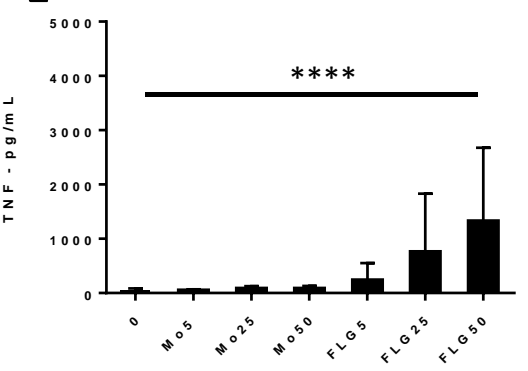

H

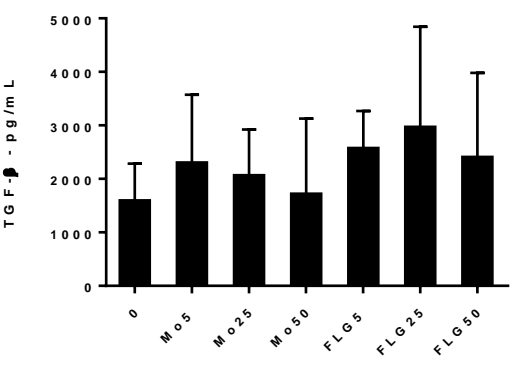

J

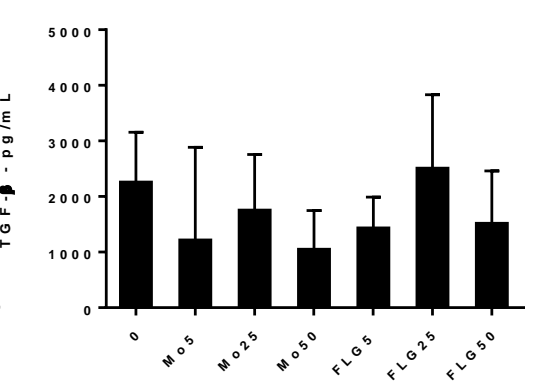

Figure 3. Macrophage cytokine secretion. Supernatants from $24 \mathrm{~h} \mathrm{MoS} 2$ (Mo) or FLG-treated $(5,25,50 \mu \mathrm{g} / \mathrm{mL}) \mathrm{M} 1$ and M2 macrophages were analyzed by ELISA to measure cytokine production. M1 pro-inflammatory cytokines (A) IL-1 $\beta$. (B) TNF. (C) IL-6. M2 proinflammatory cytokines (D) IL-1 $\beta$. (E) TNF. (F) IL-6. M1 anti-inflammatory cytokines (G) IL10. (H) TGF- $\beta$. M2 anti-inflammatory cytokines (I) IL-10. (J) TGF- $\beta$. All experiments were performed in triplicate and shown as mean $\pm \mathrm{SD}$. $* \mathrm{P}<0.05$; $* * \mathrm{P}<0.01$, $* * * \mathrm{P}<0.001$ by one-way ANOVA with Bonferroni post-tests. 


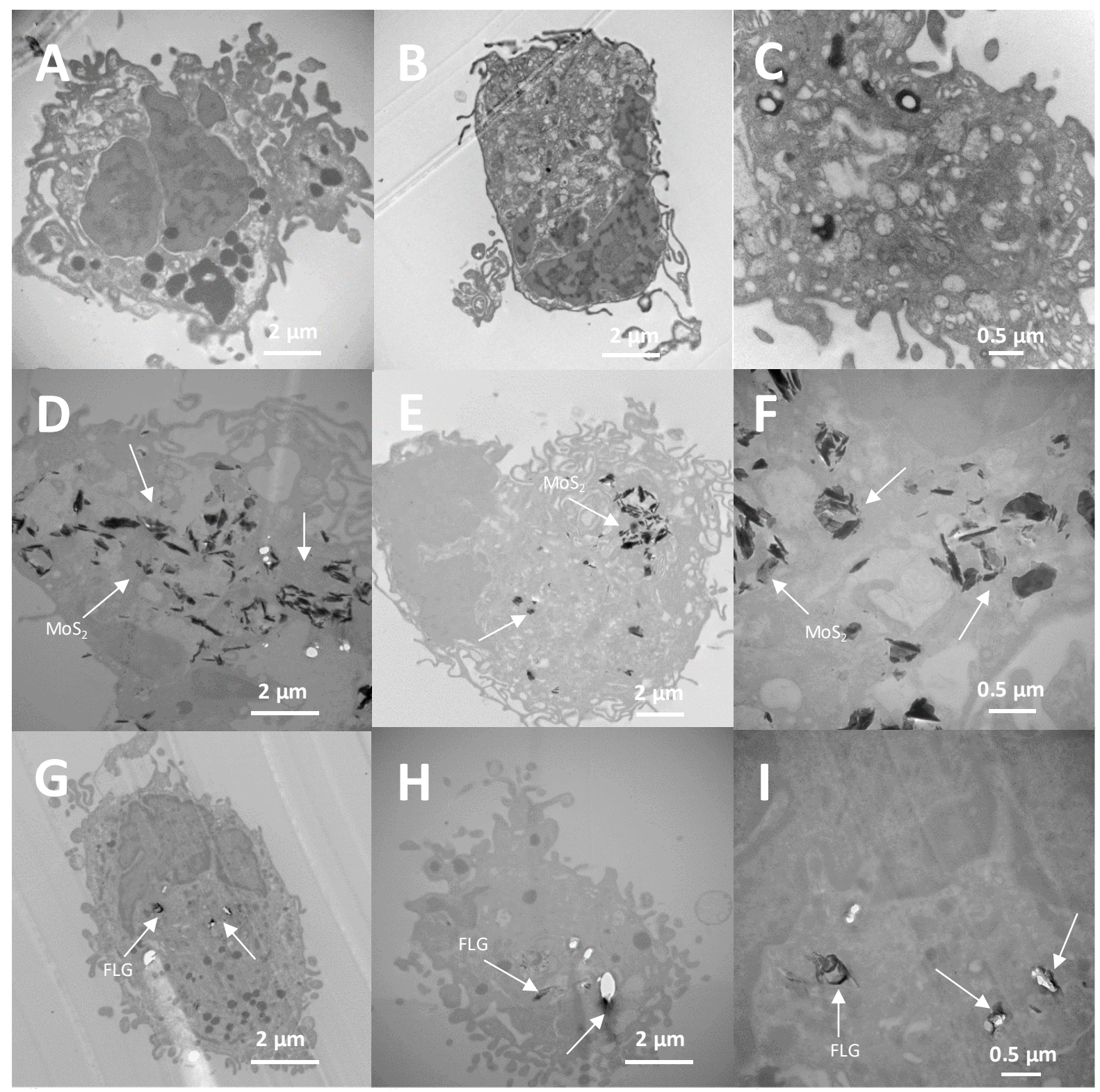

Figure 4. Macrophage transmission electron microscopy imaging. $M 1$ macrophages after $24 \mathrm{~h}$ treatment with 2D materials. (A-C) untreated (D-F) $\mathrm{MoS}_{2}$ at $50 \mu \mathrm{g} / \mathrm{mL}$ (G-I) FLG at 50 $\mu \mathrm{g} / \mathrm{mL}$. Panels $(\mathbf{C}, \mathbf{F}, \mathbf{I})$ are magnified images showing material internalization $(\mathbf{F}, \mathbf{I})$ into phagocytic vacuoles. 


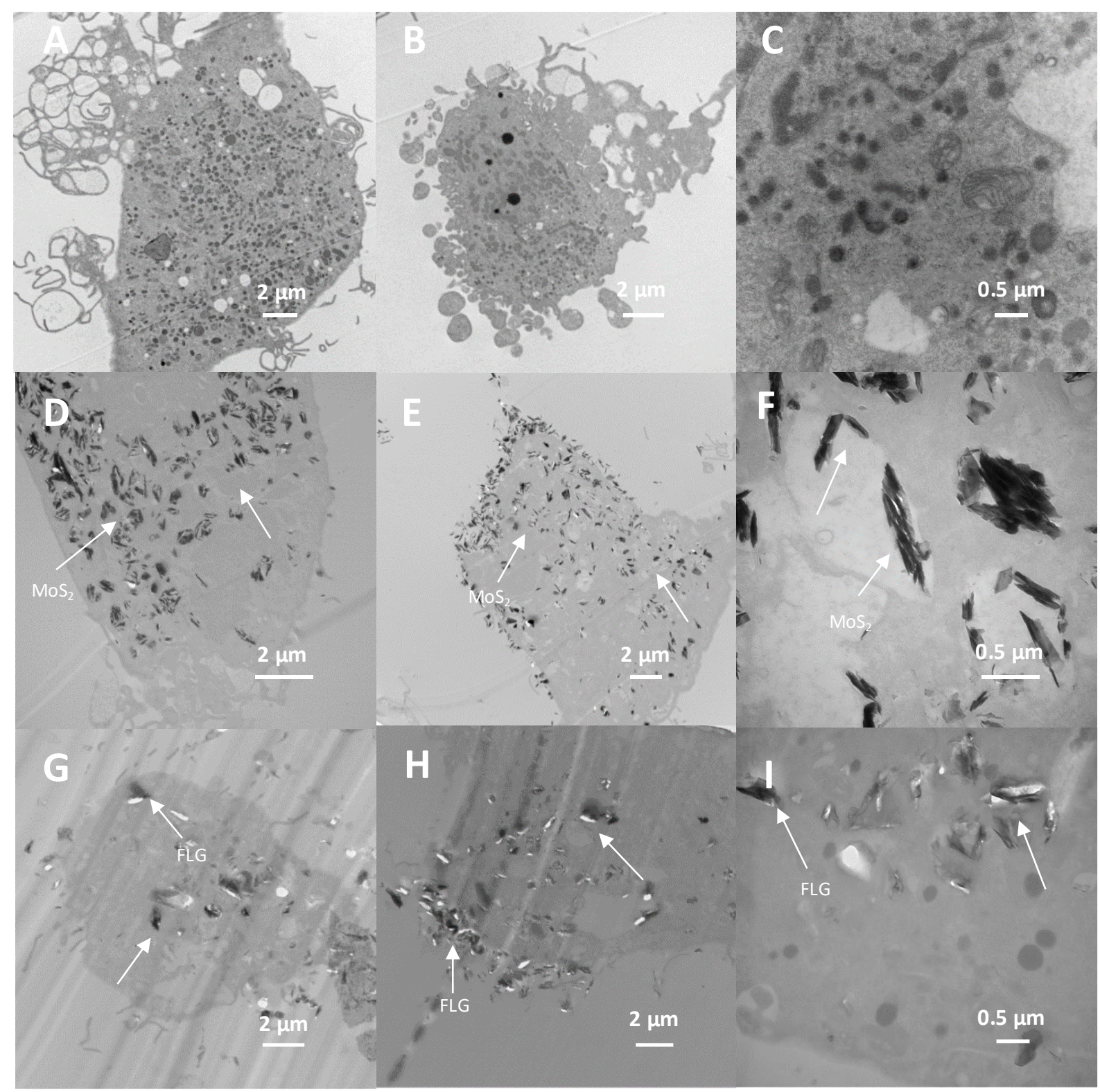

Figure 5. Macrophage transmission electron microscopy imaging. M2 macrophages after $24 \mathrm{~h}$ treatment with 2D materials. (A-C) untreated (D-F) $\mathrm{MoS}_{2}$ at $50 \mu \mathrm{g} / \mathrm{mL}$ (G-I) FLG at 50 $\mu \mathrm{g} / \mathrm{mL}$. Panels $(\mathbf{C}, \mathbf{F}, \mathbf{I})$ are magnified images showing material internalization (into phagocytic vacuoles. 


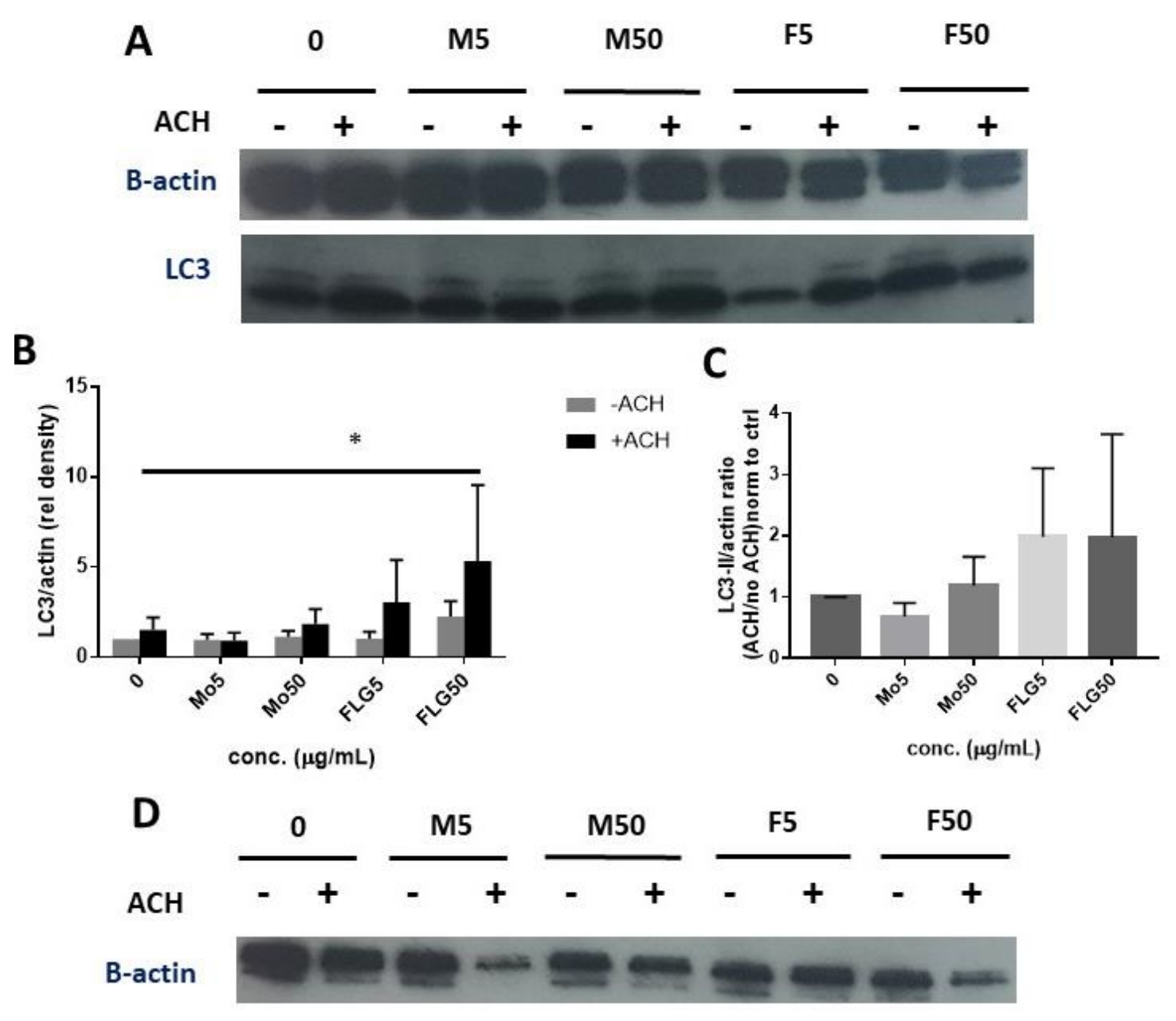

LC3
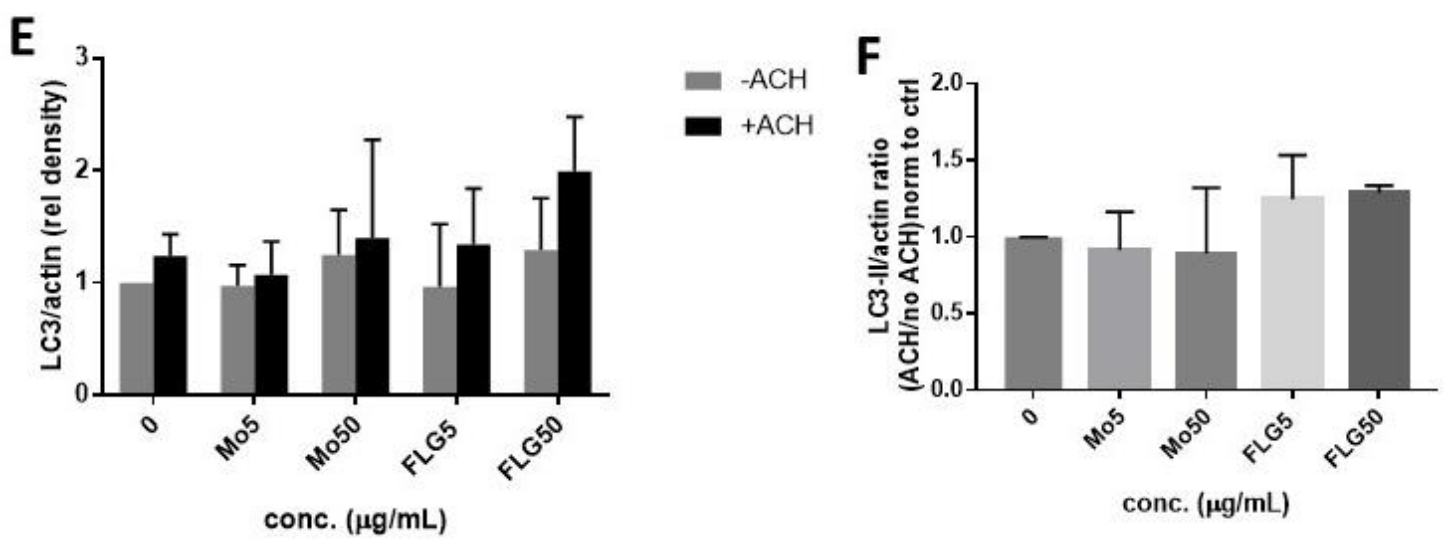

Figure 6. Autophagy analysis by western blotting. Total cell lysates from $24 \mathrm{~h} \mathrm{MoS}$ (Mo) or FLG-treated $(5,50 \mu \mathrm{g} / \mathrm{mL})$ macrophages. M1 macrophages. (A) Representative western blot of LC3 proteins and $\beta$-actin in the presence (+) and absence (-) of ammonium chloride (ACH). (B) Relative quantification of density ratio of LC3-II to $\beta$-actin. (C) Normalized densitometric evaluation of autophagic flux, ratio of $\mathrm{ACH}+$ over $\mathrm{ACH}$ - conditions., derived from (B). (D) Representative Western blot of LC3 proteins and $\beta$-actin in the presence $(+)$ and absence (-) of ammonium chloride (ACH). (E) Relative quantification of density ratio of LC3-II to $\beta$-actin. 
(F) Normalized densitometric evaluation of autophagic flux, ratio of $\mathrm{ACH}+$ over $\mathrm{ACH}-$ conditions., derived from (E) All experiments were performed thrice and shown as mean \pm SD. *P<0.05; by one-way ANOVA with Bonferroni post-tests.

A
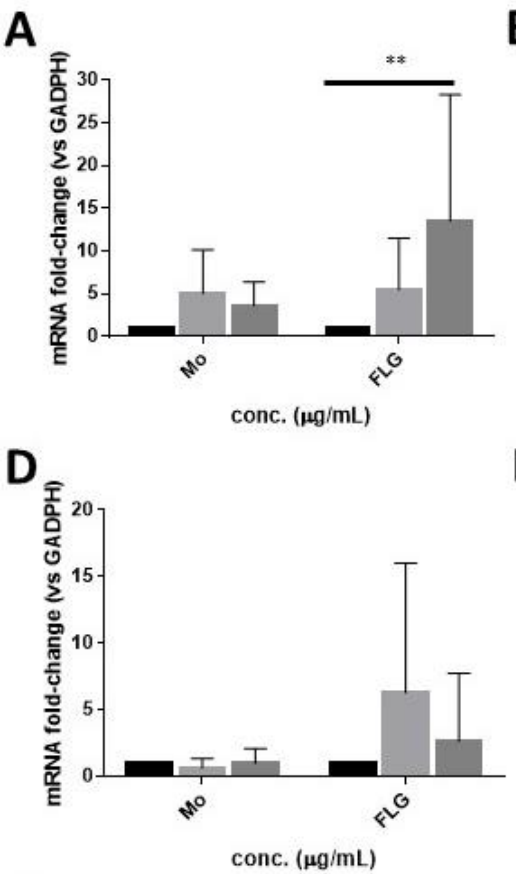

G

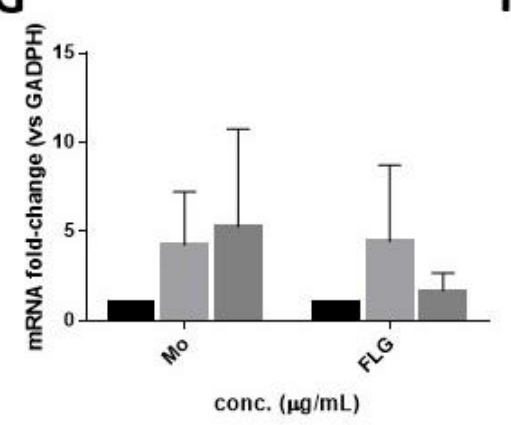

J

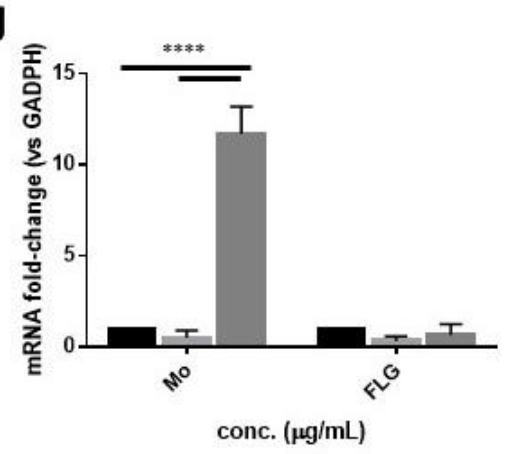

B

$\mathbf{E}$

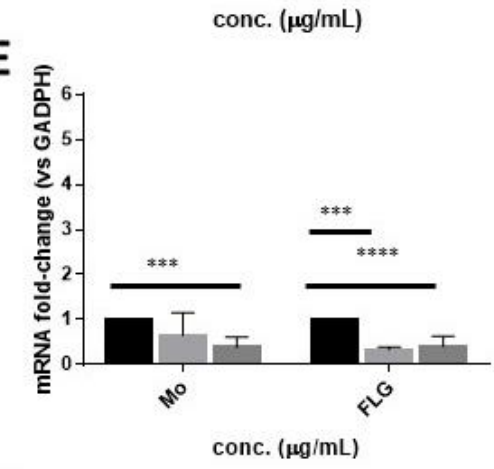

H
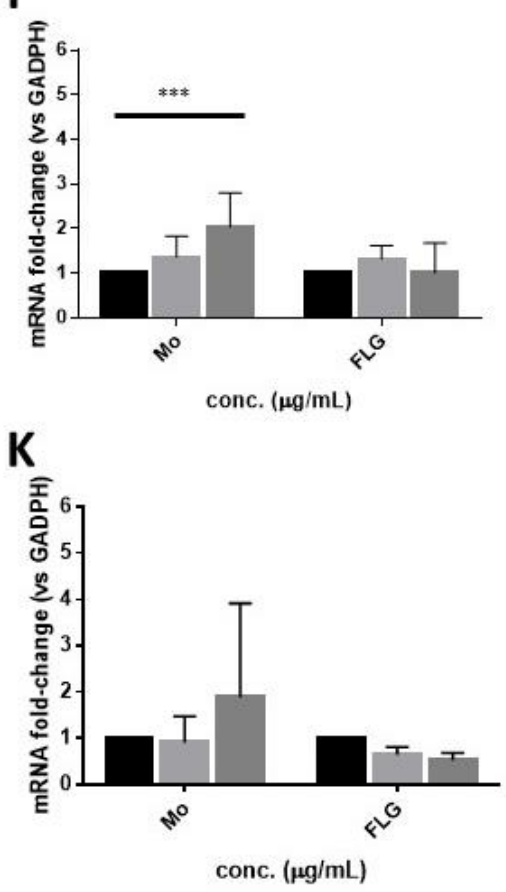

C

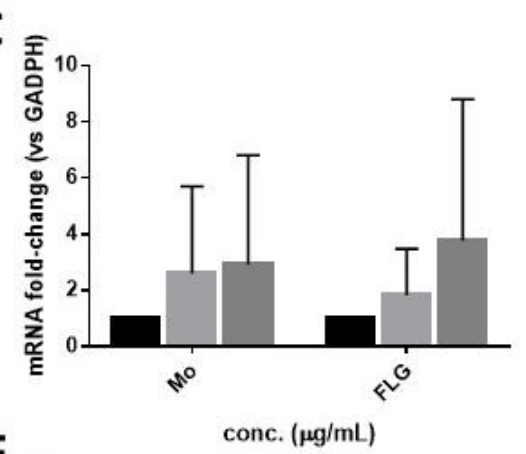

$\mathbf{F}$

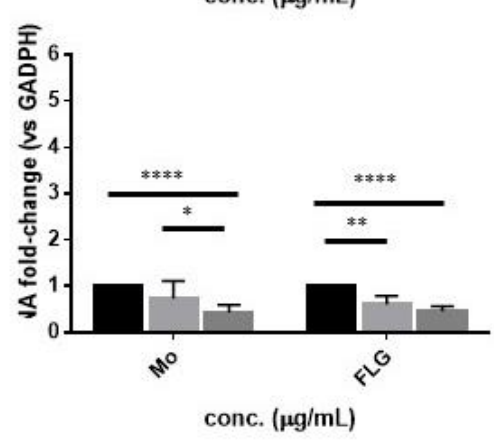

I
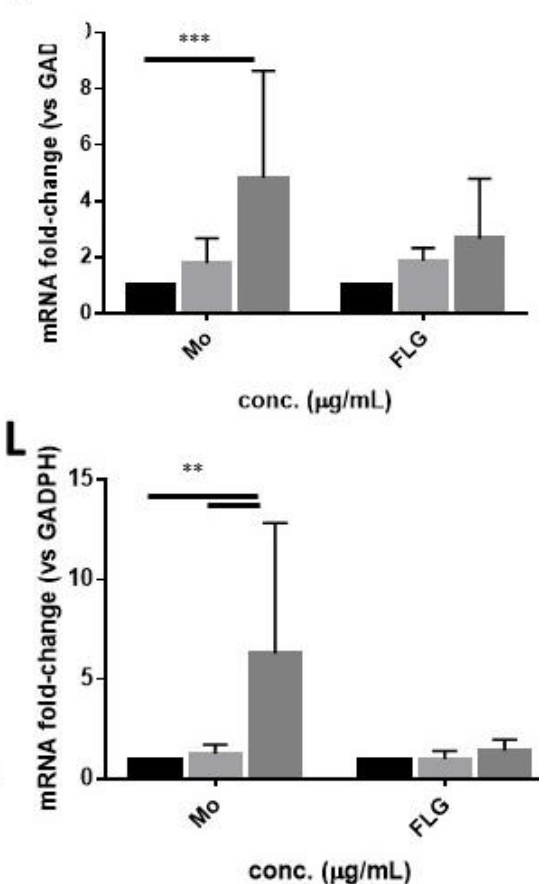

Figure 7. Autophagy and lysosomal gene expression. qPCR of cDNA derived from total RNA from $24 \mathrm{~h} \mathrm{MoS}_{2}$ (Mo) or FLG-treated $(5,25,50 \mu \mathrm{g} / \mathrm{mL}$ ) M1 and M2 macrophages. (A) M1 macrophage Atg5 expression. (B) M1 macrophage Atg 7 expression. (C) M1 macrophage Becn1 expression. (D) M2 macrophage Atg 5 expression. (E) M2 macrophage Atg 7 expression. (F) M2 macrophage Becnl expression. (G) M1 macrophage Tfeb expression. (H) M1 macrophage $C a t h B$ expression. (I) M1 macrophage CathL expression. (J) M2 macrophage Tfeb expression. (K) M2 macrophage CathB expression. (L) M2 macrophage CathL expression. Black bars correspond to untreated controls, light gray bars correspond to $5 \mu \mathrm{g} / \mathrm{mL}$, 
dark gray bars correspond to $50 \mu \mathrm{g} / \mathrm{mL}$. All experiments were performed in triplicate and shown as mean \pm SD. $* \mathrm{P}<0.05 ; * * \mathrm{P}<0.01, * * * \mathrm{P}<0.001$ by one-way ANOVA with Bonferroni post-tests. 


\section{Table of contents}

\section{Graphene and molybdenum disulfide have been increasingly used in the biomedical}

research, and it is important to check their safety in immune cells. Primary human

macrophage viability and activation were unaffected by both materials, even though they can trigger cell stress and inflammatory responses.

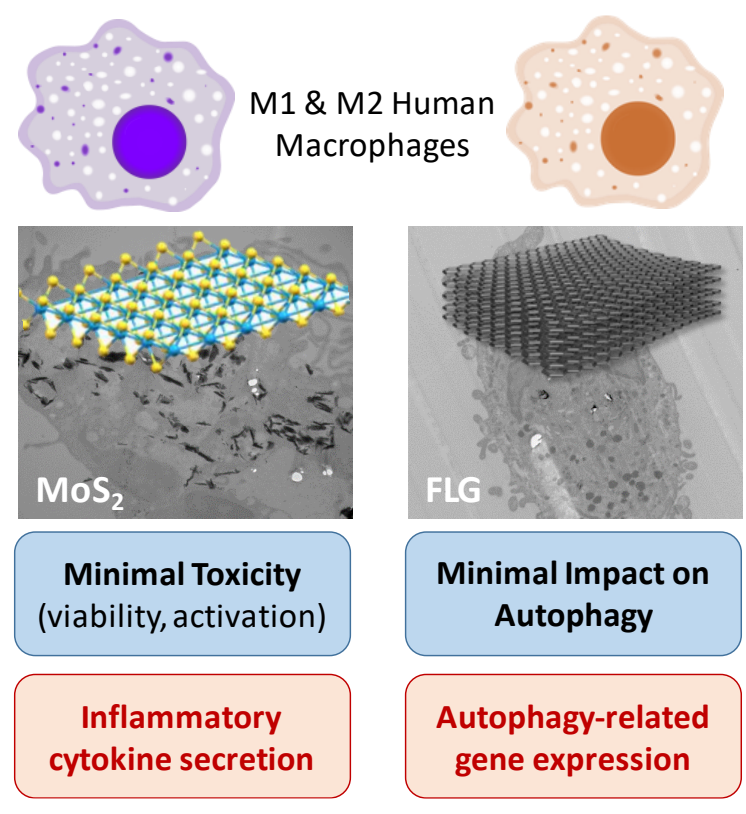

Keywords: Immune cells, carbon materials, 2D materials, cytotoxicity, safety 